\title{
Electricity Used by Office Equipment and Network Equipment in the U.S.: Detailed Report and Appendices
}

\author{
Kaoru Kawamoto, Jonathan G. Koomey, Bruce Nordman, \\ Richard E. Brown, Mary Ann Piette, Michael Ting, and Alan K. Meier \\ Energy Analysis Department \\ Environmental Energy Technologies Division \\ Ernest Orlando Lawrence Berkeley National Laboratory \\ University of California \\ Berkeley, CA 94720
}

To download this report, associated data, and related research, go to http://enduse.lbl.gov/Projects/InfoTech.html

February 2001

This work was supported by the Office of Atmospheric Programs of the U.S. Environmental Protection Agency. Prepared for the U.S. Department of Energy under Contract No. DE-AC03-76SF00098. 



\section{Table of Contents}

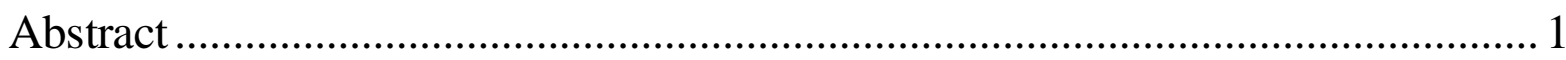

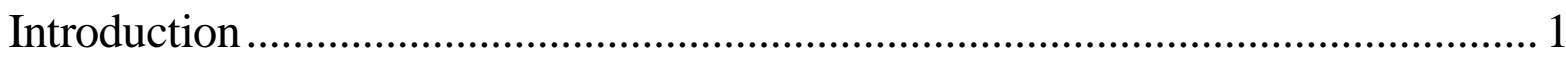

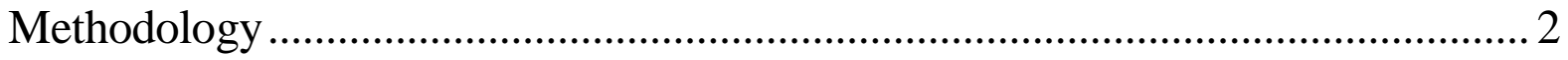

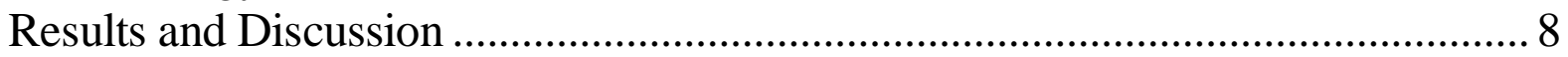

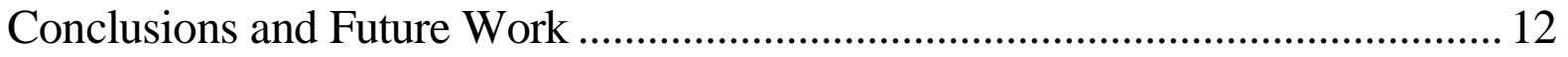

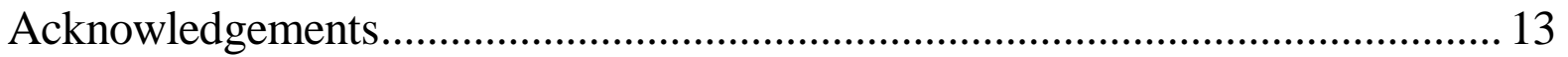

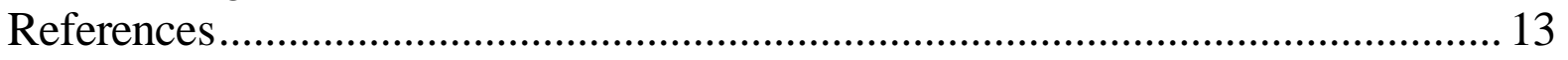

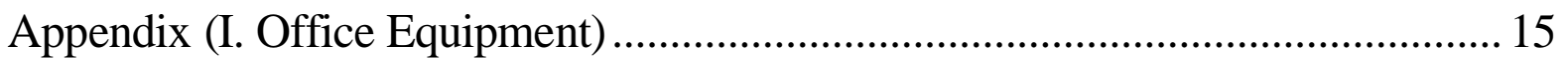

Appendix (II. Network Equipment) ................................................................ 44

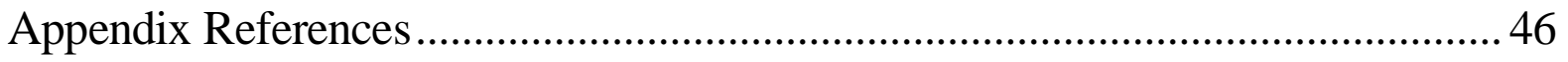





\title{
Electricity Used by Office Equipment and Network Equipment in the U.S.
}

\author{
Kaoru Kawamoto, Jonathan G. Koomey, Bruce Nordman, \\ Richard E. Brown, Mary Ann Piette, Michael Ting, and Alan K. Meier \\ Lawrence Berkeley National Laboratory
}

\begin{abstract}
In spite of the recent explosive growth in the use of office and network equipment, there has been no recent study that estimates in detail how much electricity is consumed by that equipment in the United States.

In this study, we examined energy use by office equipment and network equipment at the end of 1999. We classified office equipment into 11 types; for each type we estimated annual energy consumption for residential, commercial, and industrial use by combining estimates of stock, power requirements, usage, and saturation of power management. We also classified network equipment into six types and estimated the annual energy consumption for each type.

We found that total direct power use by office and network equipment is about 74 TWh per year, which is about $2 \%$ of total electricity use in the U.S. When electricity used by telecommunications equipment and electronics manufacturing is included, that figure rises to 3\% of all electricity use (Koomey 2000). More than $70 \%$ of the $74 \mathrm{TWh} / \mathrm{year}$ is dedicated to office equipment for commercial use. We also found that power management currently saves 23 $\mathrm{TWh} /$ year, and complete saturation and proper functioning of power management would achieve additional savings of $17 \mathrm{TWh} /$ year. Furthermore, complete saturation of night shutdown for equipment not required to operate at night would reduce power use by an additional $7 \mathrm{TWh} / \mathrm{year}$.

Finally, we compared our current estimate with our 1995 forecast for 1999. We found that the total difference between our current estimate and the previous forecast is less than $15 \%$ and identified the factors that led to inaccuracies in the previous forecast. We also conducted a sensitivity analysis of the uncertainties in our current forecast and identified the data sets that have the largest impact on our current estimate of energy use.
\end{abstract}

\section{Introduction}

Use of the Internet has spread rapidly. During the past 10 years, the number of registered domain names ${ }^{1}$ has increased from 16,000 to 15 million, and the number of world-wide web sites has increased from zero to 10 million. Meanwhile, annual shipments of computers have increased by a factor of five (Information Technology Industry Council 1998), and network devices like routers and switches have become ubiquitous. In spite of this growth, there has been no recent study that assesses in detail how much electricity is dedicated to computer equipment or network equipment in the United States. The last comprehensive study in this area is Lawrence Berkeley National Laboratory's study in 1995 (Koomey et al. 1995), prior to the Internet's emergence as an important force in the U.S. economy.

In this study, we examined energy use by office equipment and network equipment in both office and non-office settings in the U.S. We classified office equipment into 11 types. For each type, we estimated annual energy consumption (TWh/year) for residential, commercial, and industrial use by combining the stock, power requirement, usage, and saturation of power

${ }^{1}$ A definition of "domain name" can be found at $<$ http://www.register.com/faq/glossary.cgi $>$. 
management. We estimated electricity use for the case of complete saturation of power management and proper functioning of those features, as well as current practice for power management and operation. Further, we estimated energy use in the case of complete shutdown during nights and weekends of all office equipment except servers, minicomputers, mainframes, and facsimile (fax) machines. We also evaluated the uncertainties in our estimate by conducting a sensitivity analysis.

We classified network equipment into six types and estimated annual energy use (TWh/year) for each type based on sales revenue. We also surveyed energy use for the LBNL network and compared the results to our U.S. estimate to assess its reasonableness.

Finally, for energy use by commercial office equipment, we compared our current estimate with our 1995 forecast and identified the factors that led to inaccuracies in the previous forecast.

\section{Methodology}

\section{Office Equipment}

Classification. We classified office equipment into 11 types as shown in Table 1. Multi-function devices (MFDs) fall into several different categories, and although good energy data on these product categories are not available, all indications are that the energy use of each type behaves similarly to a conventional single-function type (copier, laser printer, or inkjet printer). Therefore, we allocated MFDs into appropriate single-function categories. Further, we classified each equipment type as residential, commercial, or industrial, based on the place where it is used.

\section{Table 1. Classification of Office Equipment}

\begin{tabular}{|l|l|}
\hline Equipment Type & Definition \\
\hline Portable Computer & Notebook or sub-notebook computer \\
\hline Desktop Computer & $\begin{array}{l}\text { Desktop or deskside computer that is used as a client computer and has a price } \\
\text { lower than } \$ 25,000\end{array}$ \\
\hline Server & $\begin{array}{l}\text { Desktop or deskside computer that is used as a server computer and has a price } \\
\text { lower than } \$ 25,000\end{array}$ \\
\hline Mainicomputer & $\begin{array}{l}\text { Computer whose price is between } \$ 25,000 \text { and } \$ 350,000 \text {. Peripherals such as } \\
\text { tapes and disk storage are considered part of minicomputers }\end{array}$ \\
\hline Terminal & $\begin{array}{l}\text { Computer whose price is higher than } \$ 350,000 \text {. Peripherals such as tapes and } \\
\text { disk storage are considered part of mainframes }\end{array}$ \\
\hline Display & $\begin{array}{l}\text { Non-programmable terminal usually connected to mainframes or minicomputers } \\
\text { Lisplay for desktop computer, including CRT and LCD }\end{array}$ \\
\hline Inkjet Printer & $\begin{array}{l}\text { Includes multifunction devices whose major function is laser printing } \\
\text { inkjet printing }\end{array}$ \\
\hline Copier & Includes multifunction devices whose major function is copying \\
\hline Fax & Facsimile machines \\
\hline
\end{tabular}

Definition of Power Management (PM). For computers, displays, and laser printers, we considered only one low-power mode. Although many machines have more than one PM mode, we do not believe that the power level differences and available data on the distribution of different modes justify using more than the one mode we chose.

For inkjet printers and faxes, we ignored PM, because their power requirements are usually below the ENERGY STAR ${ }^{\circledR}$ standard low-power level even without PM, and because 
many of these machines have no low-power mode.

There are many terms for operating modes. For consistency among all the equipment types, we used only three terms, "active," "low-power," and "off" as shown in Table 2. We defined active mode for copiers, faxes, and printers as the state during which devices are ready but not printing or copying. Instead of defining another mode for printing or copying, we estimated the extra energy use for copying or printing separately.

Table 2. PM Mode*

\begin{tabular}{|lllll|}
\hline Term in This Paper & Active & $\rightarrow$ Low-Power & $\rightarrow$ Off \\
\hline Term in Industry & Desktop/Portable/Server & Active $\rightarrow$ Standby & $\rightarrow$ Suspend(Sleep) & $\rightarrow$ Off \\
& Display/Terminal & Active $\rightarrow$ Sleep & $\rightarrow$ Deep Sleep & $\rightarrow$ Off \\
& Laser Printer & Ready & $\rightarrow$ Sleep & $\rightarrow$ Off \\
& Inkjet Printer & Ready & $\rightarrow$ Sleep & $\rightarrow$ Off \\
& Copier & Ready(Standby) & $\rightarrow$ Sleep(Energy Zero) & $\rightarrow$ Manual-Off/Auto-Off \\
& Fax & Ready(Standby) & $\rightarrow$ Sleep & $\rightarrow$ Off \\
\hline
\end{tabular}

*Modes shown above with strikethrough are ignored in our analysis.

General Methodology. For each type of equipment, we estimated residential, commercial, and industrial energy use as summarized in Figure 1.

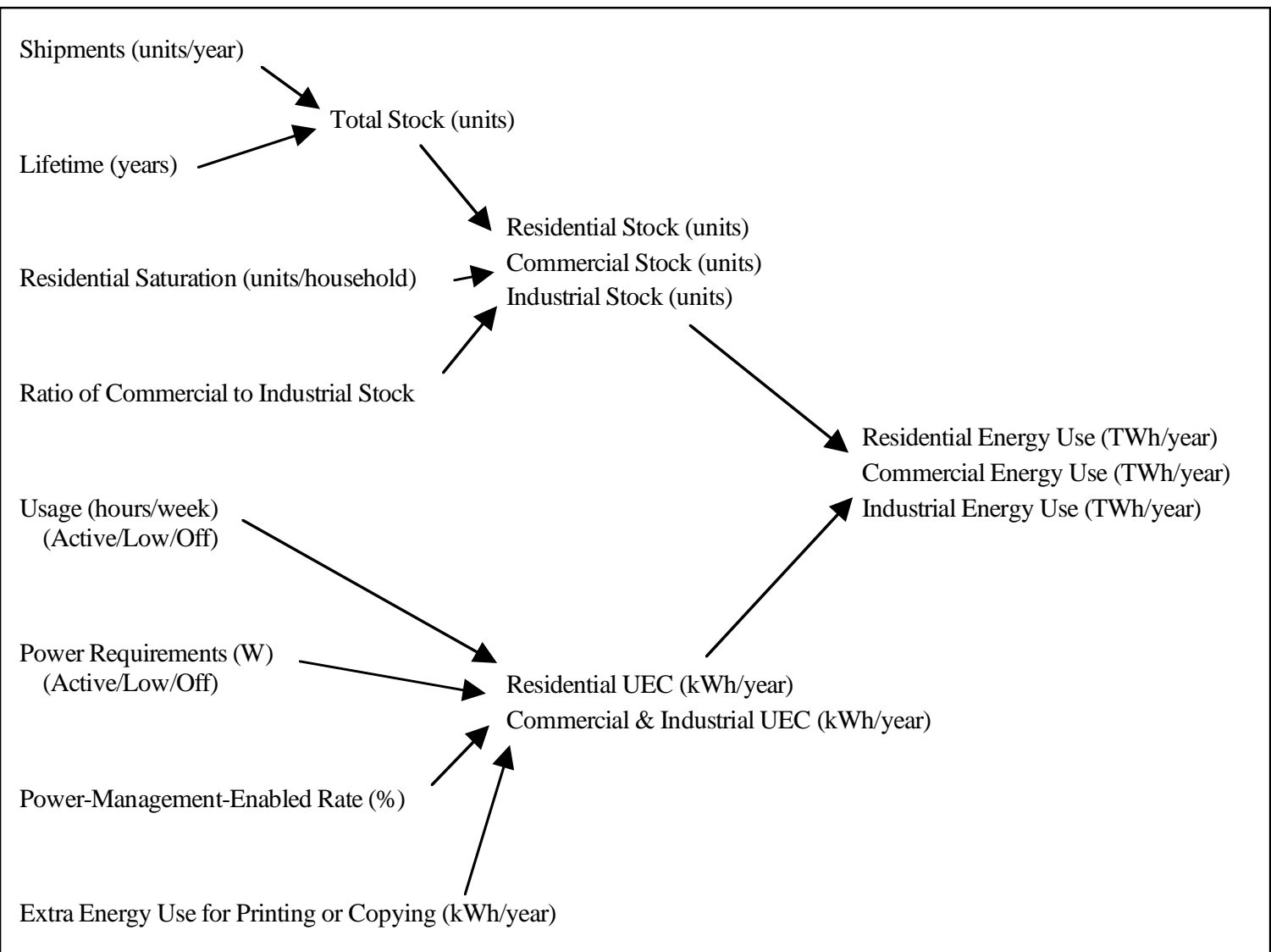

\section{Figure 1. Calculation Flow}

First, we estimated total stock using shipment data and device lifetimes. Second, we allocated total stock into residential, commercial, and industrial stocks using residential saturation rates and ratios of commercial stock to industrial stock.

Third, we estimated the average power requirement of each mode (active, low-power, 
off), average usage (mode distribution over a week), and the PM-enabled rates for residential and non-residential (i.e. commercial and industrial) use. We did not differentiate these parameters between commercial and industrial equipment. For printers, copiers, and faxes, we estimated the extra energy use for printing or copying by combining the average imaging rate (number of images printed or copied in a year) with the average energy use for each image. This estimate is important because the power used when printing or copying is much higher than the active power.

Fourth, we estimated the unit energy consumption (UEC) for residential and nonresidential devices by combining the power requirement, usage, power-management-enabled rate, and the extra energy use for printing or copying (where applicable) for each device.

Finally, multiplying the UEC by the stock, we arrived at estimates of residential, commercial, and industrial energy consumption.

Stock. First, we estimated the total stock for each type of equipment based on shipment data (Information Technology Industry Council 1998, Appliance Magazine 1999). Lifetimes were derived from a previous study (Koomey et al. 1995). The use of a single lifetime for each type of equipment is a simplification, but the available data do not justify a more complex formulation.

Second, the residential stock for each type of equipment is derived from published residential equipment saturation rates (DOE 1999, CEMA 1998, CEMA 1999). For laser printers, survey data results indicate that the residential stock is larger than the commercial stock, but we believe this result to be unrealistic. We concluded that this inaccuracy is caused by tendency of survey respondents to mistake inkjet printers for laser printers, so we corrected by assuming that half of the people responding to these surveys made this mistake.

Finally, we estimated non-residential stock by subtracting residential stock from the total stock and splitting the remainder into commercial and industrial stocks based on the ratio of commercial floor space to industrial conditioned space from Commercial Building Energy Consumption Survey in 1995 (DOE 1998) and Manufacturing Energy Consumption Survey in 1994 (DOE 1997).

Table 3 shows the stock for each type of equipment. The accuracy of commercial and industrial stock estimates depends heavily on the accuracy of the assumed lifetimes. There are also some uncertainties in the residential stock of printers because of the apparent inaccuracy of survey data. 
Table 3. Stocks of Office Equipment at the end of 1999 (millions)

\begin{tabular}{|c|c|c|c|c|}
\hline & Total & Residential & Commercial & Industrial \\
\hline Portable Computer & 22 & 16 & 5.3 & 0.76 \\
\hline Desktop Computer & 110 & 55 & 48 & 6.8 \\
\hline Server & 3.3 & 0 & 2.9 & 0.42 \\
\hline Minicomputer & 2.0 & 0 & 1.5 & 0.50 \\
\hline Mainframe & 0.11 & 0 & 0.096 & 0.011 \\
\hline Display & 110 & 55 & 48 & 6.8 \\
\hline Terminal & 13 & 0 & 10 & 3.3 \\
\hline Laser Printer & 28.0 & 6.3 & 19 & 2.7 \\
\hline$<8 \mathrm{ppm}$ & 7.8 & 6.3 & 1.3 & 0.18 \\
\hline 8-12 ppm & 8.7 & 0 & 7.6 & 1.1 \\
\hline$>12 \mathrm{ppm}$ & 11 & 0 & 10 & 1.4 \\
\hline Inkjet/Dot Printer & 74 & 50 & 21 & 2.9 \\
\hline Copier & 11 & 3.8 & 6.5 & 0.93 \\
\hline$<21 \mathrm{cpm}$ & 6.6 & 3.8 & 2.5 & 0.35 \\
\hline $21-44 \mathrm{cpm}$ & 2.8 & 0 & 2.4 & 0.35 \\
\hline$>44 \mathrm{cpm}$ & 1.9 & 0 & 1.6 & 0.24 \\
\hline Fax & 28 & 6.3 & 19 & 2.7 \\
\hline
\end{tabular}

Power Requirement. For all equipment except servers, minicomputers, and mainframes, we estimated power requirements based on our own measurements (unpublished) or measurements by others (Nordman et al. 1998, Brown 2000, and EPA 2000). To calculate power levels for copiers and laser printers, we took the weighted average of the power levels across device speeds because power levels vary considerably by the speed (images/minute) of each unit. We assumed that the power requirements for residential use are same as those for commercial and industrial use except for desktop computers, laser printers, and copiers.

For servers, we measured the power requirements for several machines and found them to range from $50 \mathrm{~W}$ to $270 \mathrm{~W}$. We estimated average power use as $75 \mathrm{~W}$.

For minicomputers and mainframes, it is difficult to estimate the average power requirement because of the wide range of power requirements for $\mathrm{CPUs}^{2}$ and the various kinds of peripherals such as tapes and disk storage.

For minicomputers, we assumed that the IBM AS/400 is the representative machine and estimated the average power requirement for the CPU based on measured data (IBM 1999). By assuming the power requirement for peripherals combined with the power requirement for the $\mathrm{CPU}$, we estimated the average power requirement for minicomputers as $1,000 \mathrm{~W}$.

For mainframes, we had two more difficulties, one of which is the recent significant decrease in power requirements and the other is the lack of measured data. We separated the stock of mainframes into the new stock shipped from 1996 until now and the old stock which were shipped before 1996. We assumed that the IBM S/390 is the representative machine for the new stock and estimated the power requirement for one type of IBM S/390 whose price is close to the average price of mainframes. We also estimated the average power requirement for the old stock based on Koomey et al. (1995). Finally, based on a weighted average of power requirements for the new stock and the old stock, we estimated the average requirement for

\footnotetext{
${ }^{2}$ We use the term "CPU" to represent the central processing units and internal drives of minicomputers and mainframes. Peripherals such as external discs and tape drives are not included in CPUs.
} 
mainframes at $10 \mathrm{~kW}$.

We also assumed that CPUs of minicomputers and mainframes are always on but their associated peripherals are off at night. We did not consider power management for minicomputers and mainframes.

In sum, there are significant uncertainties in the power requirements for servers, minicomputers, and mainframes.

PM-Enabled Rate. The PM-enabled rate is the percentage of equipment that has PM capabilities and whose power management is properly operating. Equipment that has PM capability but that has not been correctly enabled is not included in this category.

We estimated the rate for each type of equipment mainly based on the results of audits for nighttime status (Nordman et al. 1998 and Nordman et al. 2000). For portable computers and servers, we made assumptions because of the lack of data, so there are some uncertainties.

Usage (Mode Distribution). We estimated the average usage (mode distribution over a week) for each type of office equipment in the case that it has PM capability and that it is enabled. Several factors combine to determine the average mode distribution. The causative factors are the work habits of the machines' users, the configuration of PM features, and the degree to which equipment is turned off manually. We defined the following three parameters that describe those factors.

1. Daytime Length - the length of the time during which the equipment is regularly used

2. Daytime Status - whether the equipment is active, at low-power, or off during daytime

3. Nighttime Status - whether the equipment is active, at low-power, or off during nights and weekends

These parameters for commercial and industrial use are estimated mainly based on the results of power datalogging and audits for night status (Nordman et al. 1998, Nordman et al. 2000, and Brown 2000). However, we were not able to locate any comparable data about servers, minicomputers, and mainframes, so we made assumptions for those three types of equipment. The usage parameters for residential use are estimated based on the survey data (DOE 1999 and CEMA 1998), other studies (Meyer and Schaltegger 1999) and some assumptions. Although some businesses are run out of homes and some computers are provided by businesses for use at home, we folded those situations into our residential use estimate.

Based on the estimated parameters, we calculated the average mode distribution of each type of office equipment. There is significant uncertainty in the usage for servers, minicomputers, and mainframes. There are also some uncertainties in residential usage because of the lack of data.

Extra Energy Use for Printing or Copying. Extra energy use for printing or copying is the energy required beyond the energy used in active mode. We estimated this extra energy use by combining the average imaging rate ${ }^{3}$ with the average extra energy use for each image. Making assumptions about paper use rates ${ }^{4}$ and duplexing rates ${ }^{5}$, we estimated the imaging rate for each type of equipment. We also assumed the average extra energy use for each image as $1 \mathrm{Wh}$ for all

\footnotetext{
${ }^{3}$ The imaging rate is the average number of images printed or copied by each unit in a year.

${ }^{4}$ The paper use rate is the average amount of paper printed or copied by each unit in a year.

${ }^{5}$ The duplexing rate represents the ratio of images placed onto duplexed sheets to images placed onto singled-sided sheets. A $100 \%$ duplexing rate uses half as much paper as a $0 \%$ duplexing rate. Duplexing rate $=$ (imaging rate paper use rate) $* 2$ / imaging rate.
} 
the types of equipment based on Nordman et al. (1998) and Brown (2000).

Because most assumptions are based on data cited by other papers or on our own judgments, there are uncertainties. However, this methodology is potentially more accurate since total paper consumption is well known, thus limiting the inaccuracies in total energy consumption for printing or copying.

Unit Energy Consumption (UEC). UEC is the average annual energy used by each piece of equipment. The UEC for each type can be described by Equation 1.

$$
\begin{aligned}
U E C_{i}= & \left(S P M_{i} \times\left(P A_{i} \times H A_{i}+P L_{i} \times H L_{i}+P O_{i} \times H O_{i}\right) / 7\right) \times 365 / 10^{3} \\
& +\left(\left(1-S P M_{i}\right) \times\left(P A_{i} \times\left(H A_{i}+H L_{i}\right)+P O_{i} \times H O_{i}\right) / 7\right) \times 365 / 10^{3}+E P C_{i}
\end{aligned}
$$

where

$U E C_{i}=$ Unit Energy Consumption for equipment type $i(\mathrm{kWh} / \mathrm{year})$

$i=$ index for equipment type

$P A_{i}=$ Average active mode power for equipment type $i(W)$

$P L_{i}=$ Average low-power mode power for equipment type $i(W)$

$P O_{i}=$ Average off mode power for equipment type $i(W)$

$H A_{i}=$ Hours of operation in active mode for equipment type $i$ (hours/week)

$H L_{i}=$ Hours of operation in low-power mode for equipment type $i$ (hours/week)

$\mathrm{HO}_{i}=$ Hours of operation in off mode for equipment type $i$ (hours/week)

$S P M_{i}=$ Power-management-enabled rate for equipment type $i(\%)$

$E P C_{i}=$ Extra energy for printing or copying for equipment type $i(k W h / y e a r)^{6}$

$365=$ days per year

$7=$ days per week

The UEC for each type of equipment is shown in Table 4.

Table 4. Best Estimate of Unit Energy Consumption for Office Equipment in 1999

\begin{tabular}{|l|c|c|}
\hline Equipment Type & $\begin{array}{c}\text { Residential UEC } \\
(\mathrm{kWh} / \text { year })\end{array}$ & $\begin{array}{c}\text { Commercial/Industrial UEC } \\
(\mathrm{kWh} / \text { year })\end{array}$ \\
\hline Portable Computer & 8.6 & 24.6 \\
Desktop Computer & 49 & 213 \\
Server & $*$ & 560 \\
Minicomputer & $*$ & 5,840 \\
Mainframe & $*$ & 58,400 \\
Terminal & $*$ & 183 \\
Display & 57 & 205 \\
Laser Printer & 16 & 283 \\
Inkjet/Dot Printer & 22 & 74 \\
Copier & 288 & 874 \\
Fax & 70 & 119 \\
\hline
\end{tabular}

* We assume that there are no servers, minicomputers, mainframes, and terminals in the residential sector.

\section{Network Equipment}

Classification. We classified network equipment into six types as shown in Table 5. We did not include the switching equipment contained in the telephone system.

\footnotetext{
${ }^{6} E P C_{i}$ is zero for computers, displays, and terminals.
} 
Table 5. Classification of Network Equipment

\begin{tabular}{|l|l|l|}
\hline \multicolumn{2}{|l|}{ Equipment Type } & Definition \\
\hline \multirow{2}{*}{$\begin{array}{l}\text { WAN } \\
\text { Equipment }\end{array}$} & Router & Throughput-capacity is multi-gigabit. Interfaces and controllers \\
\cline { 2 - 3 } & Switch & Routers and switches usually used for LAN (e.g. Cisco 2500, \\
\hline \multirow{2}{*}{$\begin{array}{l}\text { LAN }^{8} \\
\text { Equipment }\end{array}$} & Router & 4500, 7000). \\
\cline { 2 - 3 } & Switch & Access concentrators and access servers \\
\cline { 2 - 3 } & Access Device & Passive hubs and switching hubs \\
\cline { 2 - 3 } & Hub &
\end{tabular}

General Methodology. We were unable to get any shipment data for network equipment so we had no alternative but to estimate energy use in the U.S. by using worldwide sales revenue for each equipment type. First, we estimated the domestic sales revenue during the past four years by allocating the worldwide revenue based on the ratio of the number of host names or domain names in the U.S. to the world. Second, we assumed a representative model for each equipment type and estimated the virtual stock number of the representative model by dividing the domestic revenue by the unit price of the representative model. Finally, assuming all the network equipment operates for 24 hours per day throughout the year, we estimated annual power use for each type of network equipment by the following equation:

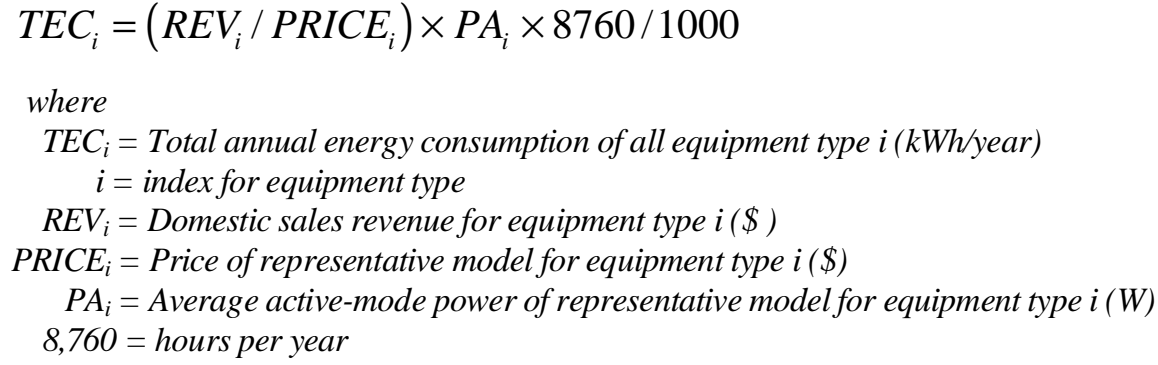

\section{Results and Discussion}

\section{Results}

Tables 6 and 7 show annual energy use for office equipment and network equipment, which totals $74 \mathrm{TWh} /$ year for both types of equipment.

Figure 2 shows the percentage of annual energy use by residential, commercial, and industrial office equipment and network equipment. Commercial office equipment accounts for more than $70 \%$ of energy use, energy use for network equipment is less than $5 \%$, and the remainder is evenly split between residential and industrial.

Figure 3 shows the percentage of annual energy consumed in active, low-power, off, and printing/copying mode. We found that $86 \%$ of all energy (64 TWh/year) is consumed in active mode, and $4 \%$ of all energy ( $3 \mathrm{TWh} / \mathrm{year}$ ) is consumed in off mode.

\footnotetext{
${ }^{7}$ WAN means Wide Area Network.

${ }^{8}$ LAN means Local Area Network.
} 
Table 6. Best Estimate of Annual Energy Use by Office Equipment in 1999 (TWh/year)

\begin{tabular}{|l|ccc|c|}
\hline Equipment Type & Residential & Commercial & Industrial & Total \\
\hline Portable Computer & 0.14 & 0.13 & 0.02 & 0.29 \\
Desktop Computer & 2.67 & 10.21 & 1.46 & 14.34 \\
Server & 0 & 1.60 & 0.23 & 1.83 \\
Minicomputer & 0 & 8.86 & 2.95 & 11.81 \\
Mainframe & 0 & 5.62 & 0.63 & 6.25 \\
Terminal & 0 & 1.83 & 0.61 & 2.44 \\
Display & 3.13 & 9.82 & 1.40 & 14.35 \\
Laser Printer & 0.10 & 5.36 & 0.77 & 6.23 \\
Inkjet/Dot Printer & 1.10 & 1.56 & 0.22 & 2.88 \\
Copier & 1.10 & 5.71 & 0.82 & 7.63 \\
Fax & 0.44 & 2.26 & 0.32 & 3.02 \\
\hline Total & 8.67 & 52.95 & 9.42 & 71.04 \\
\hline
\end{tabular}

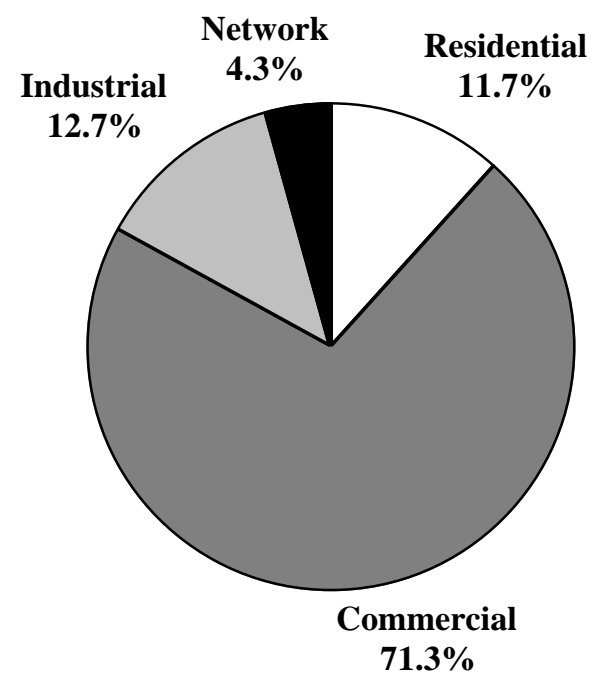

Figure 2. Percentage of Annual Energy Use by Sector at the end of 1999.

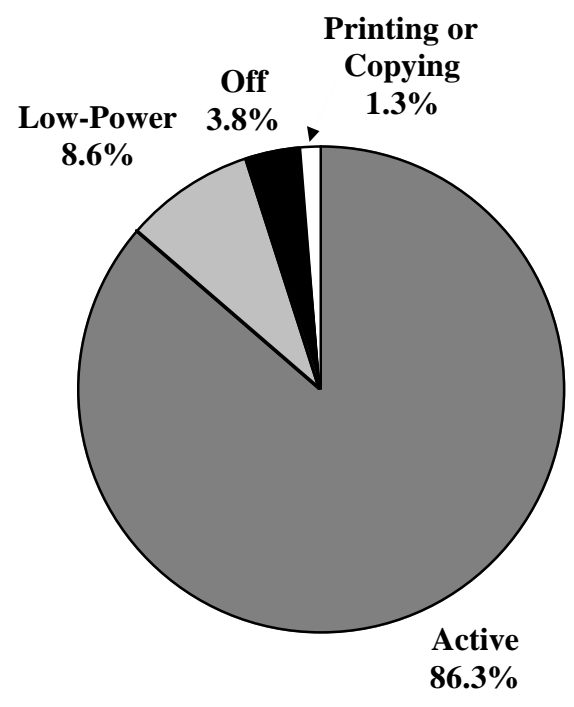

Figure 3. Percentage of Annual Energy Use by Power Mode at the end of 1999.

Table 7. Best Estimate of Annual Energy Use by Network Equipment in 1999 (TWh/year)

\begin{tabular}{|l|l|c|}
\hline & Equipment Type & Annual Energy Use \\
\hline WAN & Router & 0.05 \\
& Switch & 0.24 \\
\hline LAN & Router & 0.68 \\
& Switch & 1.31 \\
& Access Device & 0.29 \\
& Hub & 0.65 \\
\hline Total & & 3.22 \\
\hline
\end{tabular}




\section{Energy Savings by Power Management and Night Shutdown}

Figure 4 shows a breakdown of annual energy use by equipment type in the following cases: $0 \%$ saturation of PM; best estimates of current PM saturation and operation; complete saturation of properly functioning PM; and complete saturation of PM with complete night shutdown of all office equipment except servers, minicomputers, mainframes and faxes.

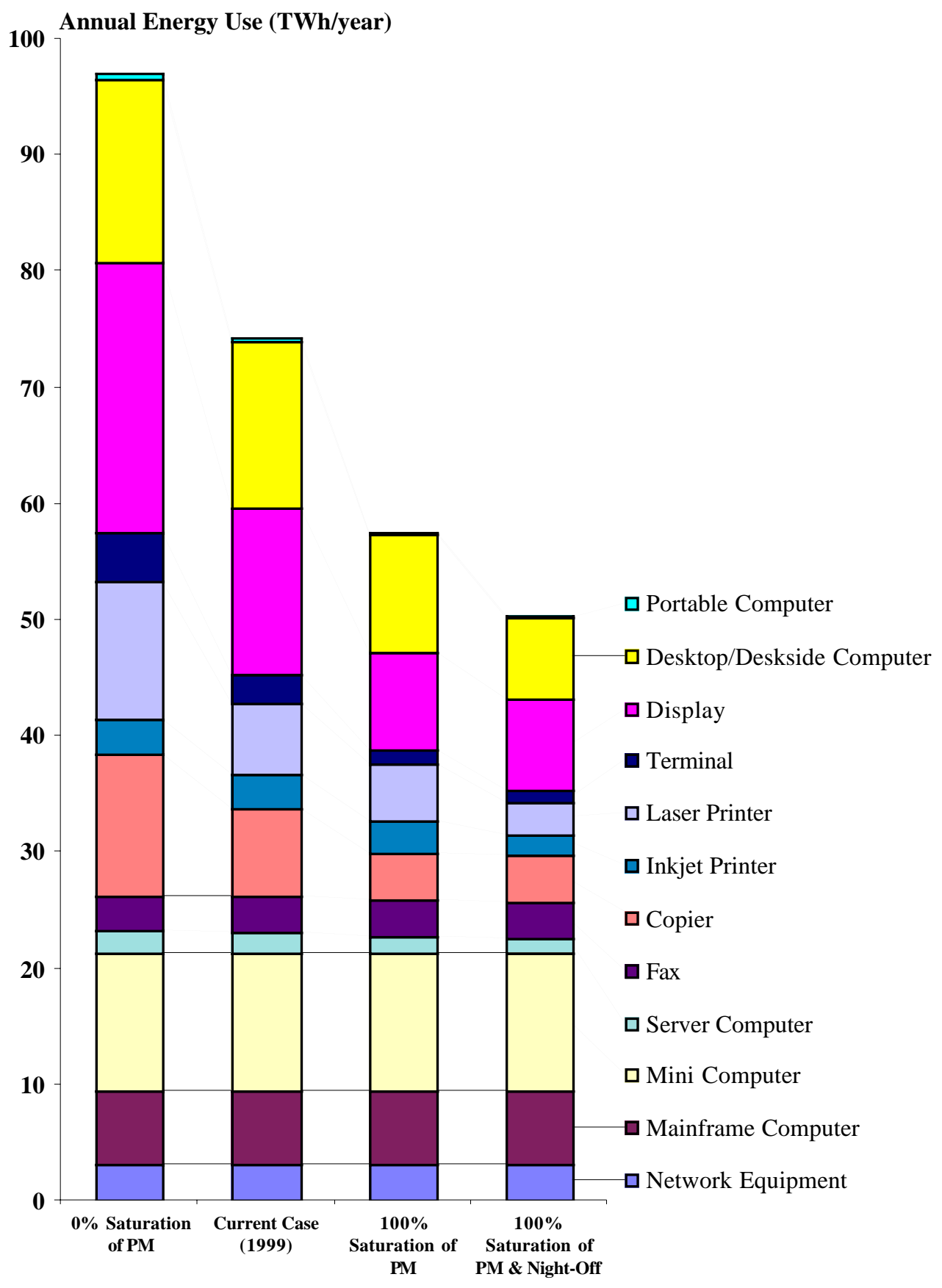

Figure 4. Electricity Use by Equipment Type as a Function of Power-Management Levels 
Current saturation of PM has achieved energy savings of 23 TWh/year, compared to the hypothetical case with $0 \%$ PM present and enabled. Complete saturation of PM (capability and enabling) would save an additional $17 \mathrm{TWh} /$ year. Most of these savings would come from desktop computers, displays and copiers since the PM-enabled rate for desktop computers is low $(=25 \%)$ and the power reductions from PM for displays and copiers are large (for displays, active power $=85 \mathrm{~W}$, low power $=5 \mathrm{~W}$; for copiers, power in auto-off is less than $10 \mathrm{~W}$ ).

Furthermore, complete saturation of night shutdown for all equipment except servers, minicomputers, mainframes, and faxes would reduce energy use by an extra $7 \mathrm{TWh} / \mathrm{year}$. Most of these savings would be achieved by night shutdown of desktop computers and laser printers since power reductions by night shutdown for desktop computers and laser printers are large (low-power level for desktop computers and laser printers is $25 \mathrm{~W}$ ) and laser printers are frequently left on at night (according to our survey, 73\% of laser printers are on at night).

\section{Uncertainty}

For all the input data for office equipment, we conducted sensitivity analyses to evaluate the uncertainty in our estimates of energy use. We estimated the error range for each piece of input data and calculated the resulting error range in our estimate of annual energy use caused by the error associated with each piece of input data. We found that the uncertainties in the following data have the largest impact on our estimate of annual energy use, with each contributing potential error greater than $2 \mathrm{TWh} /$ year:

1. Stock of commercial/industrial desktop computers, displays, minicomputers, mainframes, laser printers, and copiers;

2. Active power requirements for minicomputers;

3. Usage for commercial/industrial desktop computers, minicomputers, and displays.

To check whether our estimate for LAN network equipment is reasonable or not, we estimated the power requirement of the LBNL network equipment, which connects about 5,000 computers, and compared the result with our estimate by scaling the LBNL network to the size of all networks in the U.S. We found that the total difference in LAN network energy per personal computer was less than $20 \%$ between LBNL and the U.S. We were not able to check the accuracy of our estimate for WAN equipment though we are confident that the total error in our estimate for network equipment is less than $1.5 \mathrm{TWh} /$ year.

\section{Comparison with Our 1995 Forecast}

We compared our current estimate for commercial office equipment with our 1995 forecast for the year 1999 (Koomey et al. 1995). Results are shown in Figure 5 for the office equipment types that are common to both studies. The total difference is less than $15 \%$. Energy use for desktop computers, printers, and displays is higher than in our 1995 forecast. This difference arose because desktop computers and laser printers are left on at night more frequently than we expected and also because active power for displays is higher than we expected (active power for displays is $85 \mathrm{~W}$; while our previous forecast was $63 \mathrm{~W}$ ). There is little difference in energy use for minicomputers and mainframes. 


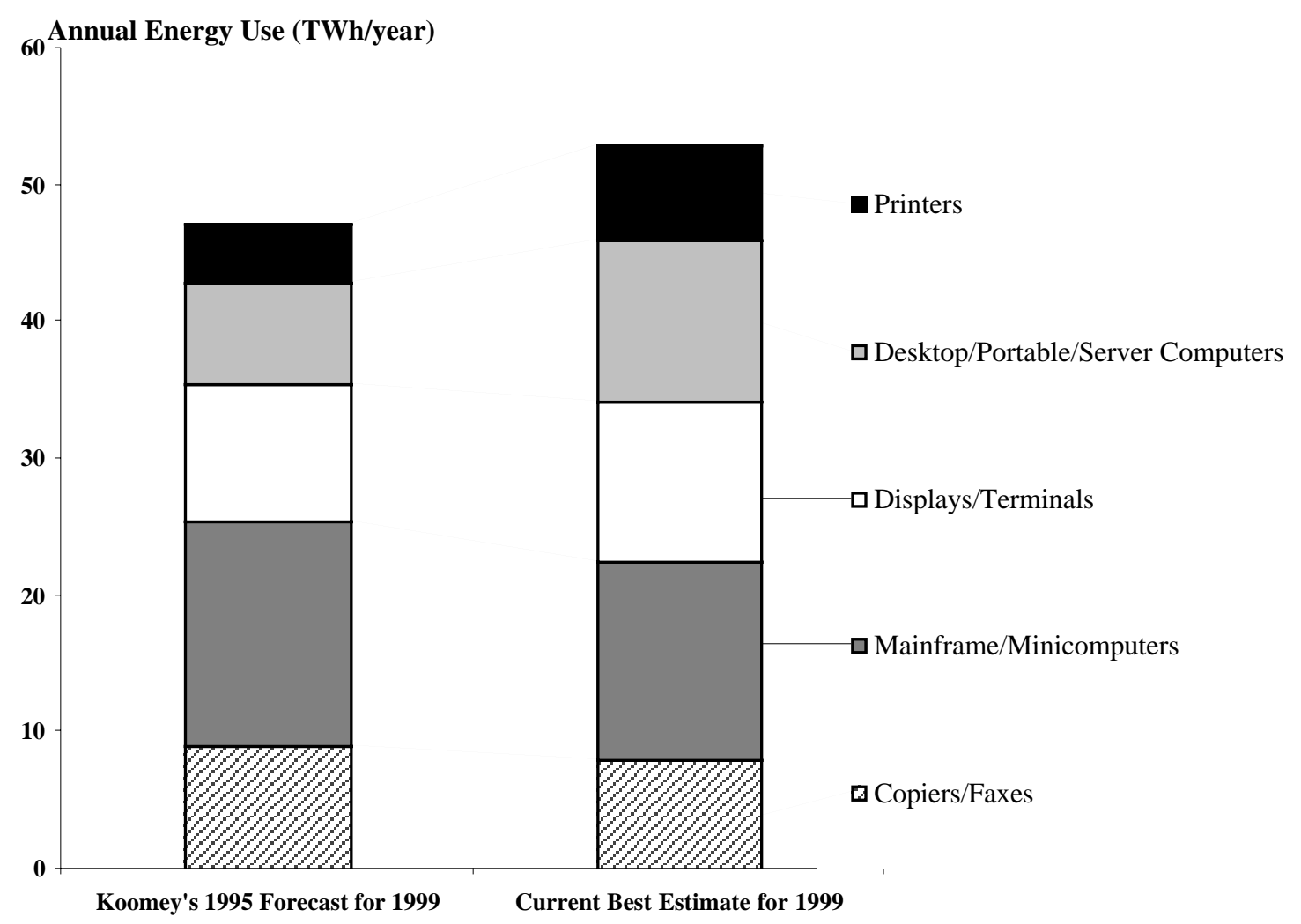

Figure 5. Comparison of Current Forecast of Commercial Office Equipment Electricity Use and 1995 Forecast (Koomey et al. 1995)

\section{Conclusions and Future Work}

Annual energy use by office and network equipment is about $74 \mathrm{TWh} / \mathrm{year}$, which is about $2 \%$ of total U.S. electricity consumption today. When electricity used by telecommunications equipment and electronics manufacturing is included, that figure rises to 3\% of all electricity use (Koomey 2000). More than $70 \%$ of the $74 \mathrm{TWh} /$ year is dedicated to office equipment for commercial use, and less than $5 \%$ is for network equipment. The rest is split equally between residential and industrial uses. About $3 \mathrm{TWh} / \mathrm{year}$, which is $4 \%$ of all the energy use, is consumed in off mode.

Current energy savings achieved by power management are estimated at $23 \mathrm{TWh}$ /year. Complete saturation and proper functioning of PM would achieve additional savings of 17 TWh/year. Furthermore, complete saturation of night shutdown for applicable equipment types would reduce power use by an extra $7 \mathrm{TWh}$ /year.

The difference between the current estimate and our previous forecast (Koomey et al. 1995 ) is less than $15 \%$. The differences are caused mainly by the fact that people leave office equipment on at night more frequently than we predicted in 1995. Equipment with PM operating may be left on at night more frequently than conventional equipment. A sensitivity analysis showed that the most important uncertainties in our current estimate involve commercial and industrial stocks of minicomputers, mainframes, desktop computers, displays, laser printers, copiers, and the usage patterns of residential desktop computers and displays.

This study estimated the energy use and the energy savings potential for current office equipment. However, office and network equipment changes rapidly. New equipment such as 
internet appliances, web phones, and palm-size computers are already available. We need to estimate energy use for such equipment in the near future. We also need to estimate the energy used by the telephone system, which is not included in our current estimates. Additionally, we need to consider that the use of office and network equipment may influence energy and resource use in indirect ways that can be important. A complete assessment of these effects is beyond the scope of this paper but is a worthy topic of future research.

\section{Acknowledgments}

This analysis was conducted principally by Kaoru Kawamoto under the supervision of Jonathan Koomey and with the advice and assistance of the other coauthors. This work was supported by the Office of Atmospheric Programs of the U.S. Environmental Protection Agency and prepared for the U.S. Department of Energy under Contract No. DE-AC03-76SF0098. We would like to thank Skip Laitner at EPA for funding this work. We would also thank Jeff Harris and Karen Rosen of LBNL and Kurt Roth of A.D. Little, Inc. for their helpful comments.

\section{References}

Appliance. 1999. Appliance $46^{\text {th }}$ Annual Report: Statistical Review. pp 51-54.

Brown, R. 2000. "Power Consumption of Commercial Printers.” Draft LBNL report.

CEMA (Consumer Electronics Manufacturing Association). 1998. "Digital Camera Interest and Awareness - November 1998." Available at <http://www.ebrain.org/>.

CEMA (Consumer Electronics Manufacturing Association). 1999. "CE Product Ownership February 1999." Available at <http://www.ebrain.org/>.

IBM (International Business Machines). 1999. "Energy Use Comparison of AS/400 Products." Available at <http://www-1.ibm.com/servers/eserver/iseries/greenpen/ecp11.htm>.

Information Technology Industry Council. 1998. Information Technology Industry Data Book, 1960-2008. Washington, D.C.: Information Technology Industry Council.

Koomey, J.G., Cramer, M., Piette, M.A., and J.H. Eto. 1995. "Efficiency Improvements in U.S. Office Equipment: Expected Policy Impacts and Uncertainties." LBNL-37383. Berkeley, CA: Lawrence Berkeley National Laboratory. Also available at $<$ http://enduse.lbl.gov/projects/offeqpt.html $>$.

Koomey, Jonathan G. 2000. Rebuttal to Testimony on 'Kyoto and the Internet: The Energy Implications of the Digital Economy'. Berkeley, CA: Lawrence Berkeley National Laboratory. LBNL-46509. August. <http://enduse.lbl.gov/projects/infotech.html〉.

Meyer \& Schaltegger AG. 1999. "Bestimmung des Energieverbrauchs von Unterhaltungselektronikgeraten, Burogeraten und Automaten in der Schweiz." St. 
Gallen, Switzerland: Federal Office for Energy.

Nordman, B., Meier, A., and M.A. Piette. 2000. "PC and Monitor Night Status: Power Management Enabling and Manual Turn-off." LBNL-46099. Berkeley, CA: Lawrence Berkeley National Laboratory.

Nordman, B., Piette, M.A., Pon, B., and K. Kinney. 1998. "It's Midnight ... Is Your Copier On?: Energy Star Copier Performance.” LBNL-41332. Berkeley, CA: Lawrence Berkeley National Laboratory.

US DOE (US Department of Energy). 1997. "Manufacturing Consumption of Energy 1994." DOE/EIA-0512(94). Washington D.C.: Energy Information Administration.

US DOE (US Department of Energy). 1998. "A Look at Commercial Buildings in 1995: Characteristics, Energy Consumption, and Energy Expenditures.” DOE/EIA-0625(95). Washington D.C.: Energy Information Administration.

US DOE (US Department of Energy). 1999. "Residential Energy Consumption Survey (RECS): Household Energy Consumption and Expenditures 1997." DOE/EIA-0632(97). Washington D.C.: Energy Information Administration.

US EPA (US Environmental Protection Agency). 2000. "Energy Star Labeled Office Equipment." Washington, DC: US EPA, Climate Protection Division, Energy Star Labeling Branch. Available at <http://www.epa.gov/appdstar/esoe/index.html $>$. 


\section{APPENDIX}

This appendix presents the detailed assumptions of the calculations presented in the main part of the report. It describes equipment lifetimes, shipments, stocks, power requirements, hourly usage, power-management-enabling rates, and extra energy used for printing and copying. It also provides a detailed uncertainty analysis and comparison with our 1995 forecast (Koomey et al., 1995). There are two major sections, one for office equipment and one for network equipment.

\section{OFFICE EQUIPMENT}

\section{Lifetimes of Office Equipment}

Equipment lifetime is a critical factor in the estimation of stocks. The meaning of "lifetime" in this context is the total amount of time equipment is used, not just by the original owner but by all subsequent owners. Furthermore, "lifetime" measures the total amount of time equipment is actually in use (not just their lifetime until disposal) since some equipment, particularly computers and printers, can linger for several years without being plugged in or turned on before being disposed.

In Koomey et al. (1995), the calculated stocks were compared with those derived from reported equipment saturations (where data were available) to help validate assumptions about equipment lifetimes. In this study, we assumed the same lifetimes as those used in Koomey et al. (1995). The average lifetime for each type of office equipment is shown in Table A-1.

Table A-1. Average Office Equipment Lifetimes

\begin{tabular}{|l|c|}
\hline Equipment Type & Lifetime (years) \\
\hline Portable Computer & 4 \\
Desktop Computer & 4 \\
Server Computer & 4 \\
Minicomputer & 8 \\
Mainframe Computer & 9 \\
Terminal & 4 \\
Display & 4 \\
Laser Printer & 6 \\
Inkjet Printer & 6 \\
Copier & 6 \\
Fax & 6 \\
\hline
\end{tabular}

\section{Shipments of Office Equipment}

The shipment data are derived from actual sales data and estimates made by the Information Technology Industry Council (1998) and Appliance Magazine (1999).

Multi-function devices (MFDs) fall into several different categories. While there are no good energy data for these categories, all indications are that the energy use of each type of MFD behaves similarly to a conventional single-function device (e.g., copier, laser printer, or inkjet printer) and so can be aggregated with these types of devices for energy estimates. Sales data generally cite MFDs separately, so we separate the MFDs by type and aggregate them as appropriate to single-function categories. 
We split the sales of laser printers and copiers respectively into three classes based on printing or copying speeds. This is useful for estimating average power requirements, because power requirements depend heavily on printing or copying speed. We could not split the sales of copiers from 1991 to 1993 because of a lack of data. However, we could nonetheless estimate the stock of copiers by assuming that the average lifetime of copiers is 6 years.

We did not need sales data for displays, because we assumed the stock of displays is same as that of desktop computers.

Table A-2 shows shipments of each type of office equipment from 1991 to 1999.

Table A-2. Office Equipment Sales from 1991 to 1999 (thousands)

\begin{tabular}{|c|c|c|c|c|c|c|c|c|c|}
\hline Equipment Type & 1991 & 1992 & 1993 & 1994 & 1995 & 1996 & 1997 & 1998 & 1999 \\
\hline Portable Computer & 1,711 & 2,111 & 2,632 & 3,533 & 4,268 & 5,190 & 6,025 & 6,665 & 7,332 \\
\hline Desktop + Server & 7,821 & 9,763 & 13,059 & 14,756 & 18,109 & 21,393 & 25,775 & 30,035 & 35,239 \\
\hline Minicomputer & 237 & 242 & 247 & 252 & 256 & 252 & 263 & 255 & 255 \\
\hline Mainframe & 12 & 12 & 12 & 12 & 11 & 12 & 12 & 12 & 12 \\
\hline Terminal & 3,005 & 3,130 & 3,225 & 3,310 & 3,350 & 3,300 & 3,310 & 3,340 & 3,380 \\
\hline Laser Printer & 2,900 & 2,900 & 3,350 & 4,213 & 4,323 & 4,445 & 4,672 & 5,065 & 5,269 \\
\hline$<8 \mathrm{ppm}$ & 1,000 & 1,200 & 1,700 & 1,747 & 1,816 & 1,647 & 1,259 & 801 & 485 \\
\hline $8-12 \mathrm{ppm}$ & 1,900 & 1,700 & 1,000 & 1,130 & 1,095 & 1,048 & 1,640 & 1,808 & 2,008 \\
\hline$>12 \mathrm{ppm}$ & 0 & 0 & 650 & 1,336 & 1,413 & 1,723 & 1,773 & 2,457 & 2,775 \\
\hline Inkjet Printer & 836 & 1,700 & 3,500 & 5,754 & 9,041 & 9,244 & 13,081 & 16,479 & 20,475 \\
\hline Copier & 1,444 & 1,466 & 1,523 & 1,630 & 1,701 & 1,898 & 1,954 & 2,011 & 2,064 \\
\hline$<21 \mathrm{cpm}$ & & & & 1,059 & 1,052 & 1,115 & 1,127 & 1,133 & 1,137 \\
\hline $21-44 \mathrm{cpm}$ & & & & 359 & 390 & 461 & 488 & 519 & 541 \\
\hline$>44 \mathrm{cpm}$ & & & & 212 & 258 & 322 & 339 & 359 & 386 \\
\hline Fax & 1,966 & 2,141 & 2,386 & 2,526 & 2,778 & 4,345 & 5,529 & 6,082 & 6,690 \\
\hline
\end{tabular}

\section{Residential Stock of Office Equipment}

Portable Computers, Desktop Computers, and Displays. According to the Consumer Electronics Manufacturing Association (CEMA), 42\% of U.S. households had one desktop computer, and 5.7\% of U.S. households had more than one desktop computer in 1999. CEMA also says $13 \%$ of U.S. households had one portable computer, and 1.3\% of U.S. households had more than one portable computer in 1999 (CEMA 1999). According to Morisette (1999), 52 million households had at least one computer (desktop or portable computer) in 1999. According to the U.S. Department of Energy (DOE) (1999), 35.6 million households had at least one computer (desktop or portable computer) in 1997. Since there has been explosive growth in the residential stock of computers over the last five years, the DOE data appear outdated. Although the CEMA numbers appear high, only CEMA explicitly reports the saturation of portable computers, so we use the CEMA data for our best estimate.

Assuming that all households that have more than one desktop or portable computer have two desktop or two portable computers, respectively, we estimated the residential saturation of desktop and portable computers as 0.53 and 0.16 units/household, respectively. The number of U.S. households is estimated to be about 101 million in 1998 (U.S. Census Bureau 1999). Multiplying the residential saturation of computers by the number of U.S. households, we estimated the residential stock of desktop and portable computers as 55 million and 16 million, respectively. 
We assumed the residential stock of displays is same as that of desktop computers.

Laser Printers and Inkjet Printers. According to CEMA (1998), 16\% or 16.2 million U.S. households have laser printers. According to US DOE (1999), 12.6 million households had laser printers in 1997. Both the CEMA and DOE estimates account for more than half of the total stock of laser printers (even excluding MFDs, in the case of DOE). In other words, both of these survey results indicate that the residential stock of laser printers is larger than the commercial stock. However, we believe this result is unrealistic. We conclude that the inaccuracy is a result of the tendency of survey respondents to mistake inkjet printers for laser printers. We assumed that this error was made in $50 \%$ of cases; therefore, we estimated the residential stock of laser printers at 6.3 million, which is half of the DOE estimate. We assumed that all residential laser printers are low-speed models $(<8$ pages per minute or $\mathrm{ppm})$.

To estimate the residential stock of all types of printers, we assumed that $80 \%$ of residential computers (including both desktop and portable computers) have printers. Our estimate of the total stock of residential printers was thus 56.5 million.

Finally, by subtracting the residential stock of laser printers from the total stock of residential printers, we estimated the residential stock of inkjet printers as 50.2 million.

Copiers and Faxes. According to DOE (1999), 3.8 million households had copiers and 6.3 million households had faxes in 1997. Assuming there are no households that have more than one copier or fax, we estimated the residential stock of copiers and faxes as 3.8 million and 6.3 million, respectively. We also assumed that all residential copiers are low-speed models $(<21$ copies per minute or $\mathrm{cpm})$.

\section{Separating the Stock of Servers from Desktop Computers}

Computers can be generally classified into client-use and server-use computers. Most minicomputers and mainframes are server-use computers, but there are both client- and serveruse computers among microcomputers (computers whose price are lower than $\$ 25,000$ ). The usage and power requirements are different for client- and server-use computers, so we divided the stock of microcomputers into these two categories.

As defined in Table 1, client-use desktop-deskside microcomputers (desktop-deskside computers whose price is lower than $\$ 25,000$ ) are referred to here as "desktop computers" and server-use desktop-deskside microcomputers are referred to as "servers".

From Table A-1 and A-2, we calculated the total stock of desktop computers and servers combined (112 million). By subtracting our stock estimate for residential desktop computers (55 million) and assuming that all servers are used in non-residential applications, we arrive at a stock estimate of 58 million for all non-residential computers (desktops and servers). We then used Tables A-1 and A-2 to calculate the stocks of minicomputers and mainframes (2.0 and 0.11 million, respectively). Next we assumed that the total stock of server-use computers (including servers, minicomputers, and mainframes) is $10 \%$ of the stock of non-residential desktop computers, based on forecasts of server stocks published by the Business Technology Association (2000). We then estimated the stock of server-use computers and non-residential desktop computers at 5.45 million and 54.6 million, respectively. Finally, by subtracting the total 
stock of minicomputers and mainframes from the stock of server-use computers, we estimated the stock of servers at 3.33 million.

\section{Allocating Non-Residential Stock into Commercial and Industrial Stocks}

For all types of equipment except minicomputers, mainframes, and terminals, we assumed that the ratio of commercial stock to industrial stock is equal to the ratio of commercial floor space to industrial conditioned floor space. According to DOE (1998), total commercial floor space in the U.S. is about 60 billion square feet. According DOE (1997), total industrial conditioned floor space is 8.4 billion square feet. Based on these data, we estimated the ratio of commercial stock to industrial stock at $7: 1$.

For minicomputers, mainframes, and terminals, we assumed the same ratio as used in Koomey et al. (1995).

Table A-3 shows the commercial and industrial shares of non-residential office equipment stock. We split non-residential stock into commercial and industrial stocks based on these ratios.

Table A-3. Commercial and Industrial Shares of Non-Residential Office Equipment Stock

\begin{tabular}{|l|c|c|}
\hline Equipment Type & Industrial Share & Commercial Share \\
\hline Portable Computer & $12.5 \%$ & $87.5 \%$ \\
Desktop Computer & $12.5 \%$ & $87.5 \%$ \\
Server & $12.5 \%$ & $87.5 \%$ \\
Minicomputer & $25.0 \%$ & $75.0 \%$ \\
Mainframe & $10.0 \%$ & $90.0 \%$ \\
Terminal & $25.0 \%$ & $75.0 \%$ \\
Display & $12.5 \%$ & $87.5 \%$ \\
Laser Printer & $12.5 \%$ & $87.5 \%$ \\
Inkjet Printer & $12.5 \%$ & $87.5 \%$ \\
Copier & $12.5 \%$ & $87.5 \%$ \\
Fax & $12.5 \%$ & $87.5 \%$ \\
\hline
\end{tabular}

\section{Power Requirements of Office Equipment}

General Methodology. For all equipment types except servers, minicomputers, and mainframes, we estimated the power requirements based primarily on our own measurements or measurements made by others. To calculate power levels for copiers and laser printers, we use a weighted average of power levels across device speeds since power levels vary considerably by the speed (images/minute) of each unit.

We assumed that the power requirements for commercial and industrial equipment are the same. We also assumed that the power requirements for residential equipment are the same as those for commercial and industrial use except for desktop computers, laser printers, and copiers.

Results. Table A-4 shows the weighted average power requirement for each type of office equipment. 
Table A-4. Power Requirements for Office Equipment

\begin{tabular}{|lc|c|c|c|}
\hline Equipment Type & & $\begin{array}{c}\text { Active } \\
(W)\end{array}$ & $\begin{array}{c}\text { Low-Power } \\
(W)\end{array}$ & $\begin{array}{c}\text { Off } \\
(W)\end{array}$ \\
\hline Portable Computer & & 15 & 3 & 2 \\
Desktop Computer & Residential Use & 50 & 25 & 1.5 \\
& Commercial/Industrial Use & 55 & 25 & 1.5 \\
Server & & 75 & 25 & 1.5 \\
Minicomputer & & 1,000 & 500 & 0 \\
Mainframe & & 10,000 & 5,000 & 0 \\
Terminal & & 75 & 5 & 0.5 \\
Display & & 85 & 5 & 0.5 \\
Laser Printer & Residential Use & 30 & 20 & 1 \\
& & 77 & 25 & 1 \\
Inkjet Printer & Commercial/Industrial Use & 17 & $*$ & 2 \\
Copier & & 115 & 62 & 1.5 \\
& Residential Use & 185 & 76 & 8.7 \\
Fax & Commercial/Industrial Use & 11 & $*$ & 0 \\
\hline
\end{tabular}

\section{Notes on Portable Computers}

Active Mode - According to measurements by Lawrence Berkeley National Laboratory (LBNL), the active-mode power requirements of portable computers range from $12 \mathrm{~W}$ to 22 $\mathrm{W}$ when the battery is fully charged. We estimated the average active-mode power requirement at $15 \mathrm{~W}$. Because of the limited set of measurements, there is uncertainty associated with this estimate.

Low-Power Mode - According to measurements by LBNL, the power requirements of portable computers in low-power modes range from $1.5 \mathrm{~W}$ to $6 \mathrm{~W}$ when the battery is fully charged. According to Nordman et al. (1997), the average power requirement for low-power mode is $3 \mathrm{~W}$. We estimated the average power requirement in low-power mode at $3 \mathrm{~W}$. Because of the limited set of measurements, there is uncertainty associated with this estimate.

Off Mode - According to a measurement by LBNL, off-mode power requirements range from $1.5 \mathrm{~W}$ to $2 \mathrm{~W}$ when the battery is fully charged. We estimated the average off-mode power requirement as $1.5 \mathrm{~W}$. Because of the limited number of measurements, there is uncertainty associated with this estimate.

\section{Notes on Desktop Computers}

Active Mode - The average active power requirement of PCs varies considerably, with some machines using less than $30 \mathrm{~W}$ and others using more than $55 \mathrm{~W}$. According to the specification tables for IBM PCs, the average active power requirements of new home and business PCs are about $50 \mathrm{~W}$ and $65 \mathrm{~W}$, respectively. According to measurements by LBNL, the average active power requirement of Macintoshes, Pentium PCs, and pre-Pentium PCs are $47 \mathrm{~W}, 54 \mathrm{~W}$, and $50 \mathrm{~W}$, respectively. We estimated the average active power requirements of the residential and non-residential desktop computer stock at $50 \mathrm{~W}$ and 55 $\mathrm{W}$, respectively.

Low-Power Mode - According to the U.S. Environmental Protection Agency (EPA) (2000), the average power requirement of new ENERGY STAR compliant PCs in low-power mode is 
about $25 \mathrm{~W}$. We estimated the average low-power mode power requirement of desktop computers at $25 \mathrm{~W}$. We assumed that there is no difference in the power requirements of residential and non-residential desktop computers in low-power mode.

Off Mode - According to measurements by LBNL, the off-mode power requirements of Macintosh computers range from $2 \mathrm{~W}$ to $3 \mathrm{~W}$, and the off-mode power requirement of PCs is less than $1 \mathrm{~W}$. We estimated the average off-mode power requirement of desktop computers at $1.5 \mathrm{~W}$. Because of the limited number of measurements, there is uncertainty associated with this estimate. We assumed there is no difference in the off-mode power requirements of residential and non-residential desktop computers.

\section{Notes on Server Computers}

Active Mode - The average active power requirement for server computers varies considerably, since some servers are simply high-end regular PCs while others are specifically manufactured as servers and have more capabilities and higher power demand. The line between a high-end server and a minicomputer is not clear.

According to measurements by LBNL, the active-mode power requirements of server computers range from $50 \mathrm{~W}$ to $270 \mathrm{~W}$. Server computers whose power requirements are higher than $100 \mathrm{~W}$ usually have more than one CPU. We estimated the average active-mode power requirement at $75 \mathrm{~W}$. Because of the limited number of measurements, there is uncertainty associated with this estimate.

Low-Power Mode, Off Mode - We assumed the power requirements for server computers in low-power mode and off mode are same as those for desktop computers. Again because of the limited number of measurements, there is uncertainty associated with this estimate.

\section{Notes on Mainframes (with Peripherals)}

Active Mode - It is difficult to estimate the average power requirement of mainframe computers because of:

1. The wide range of power requirements for Central Processing Units ${ }^{1}$ (CPUs) and the varying the number of CPUs used in mainframe computers.

2. The various kinds of peripherals associated with mainframes such as external discs and tapes.

3. The recent decreases in power requirements resulting from the emergence of C-MOS technology and internal disc systems.

4. The lack of measured data.

We separated the stock of mainframes into stock shipped between 1996 and present (55\%) and stock shipped before 1996 (45\%).

We assumed that the IBM S/390 is a representative machine for new stock based on sales data

\footnotetext{
${ }^{1}$ We use the term "CPU" for the central processing units, motherboards, and power supplies of minicomputers and mainframes. Peripherals such as tape drives and external disks are not included in CPUs.
} 
and its close-to-the-average price for mainframes. We estimated the power requirement of the $\mathrm{CPU}$ and internal discs at $2.0 \mathrm{~kW}$ by assuming that the power requirement is approximately half of the rated power requirement. We also assumed the power requirement for peripherals (tapes, etc.) is $2.0 \mathrm{~kW}$. Thus, the average power requirement of the new stock of mainframes plus peripherals was estimated at $4.0 \mathrm{~kW}$.

Based on Koomey et al. (1995), we estimated the average power requirement of the old stock of mainframes with peripherals at $13.3 \mathrm{~kW}$.

Finally, based on a weighted average of power requirements for the new and old stock, we estimated the average power requirement for mainframes at $10 \mathrm{~kW}$. There is significant uncertainty in this estimate.

Low-Power Mode - Based on Koomey et al. (1995), we define the low-power mode for mainframes as the time when peripherals are off at night. Low-power mode of mainframes does not mean power management; it means that peripherals are off but CPUs are still on.

We estimated that the average power requirement for mainframes in low-power mode is $5.0 \mathrm{~kW}$ since the power requirement of peripherals accounts for about half of the active-mode power requirements of mainframes. There is significant uncertainty in this estimate.

Off Mode - Off mode for mainframes describes machines that have useful life but are not plugged in, such as spares. Therefore we assumed the off-mode power requirement of mainframes to be $0 \mathrm{~W}$.

\section{Notes on Minicomputers (with Peripherals)}

Active Mode - It is difficult to estimate the average power requirement of minicomputers because of:

1. The wide range of power requirements for CPUs and the varying number of CPUs used in minicomputers.

2. The various kinds of peripherals associated with minicomputers such as external discs and tapes.

Based on sales data, we assumed that the IBM AS/400 is a representative minicomputer machine. We estimated the average power requirement of the CPU and internal discs as $500 \mathrm{~W}$ based on measured data (IBM 1999). By assuming that the power requirement for peripherals is also 500 $\mathrm{W}$, we estimated the average power requirement of minicomputers as $1.0 \mathrm{~kW}$. There is significant uncertainty in this estimate.

Low-Power Mode - As with mainframes, the low-power mode of minicomputers does not mean power management; it means that peripherals are off but CPUs are still on. We estimated that the average power requirement for minicomputers in low-power mode is 500 $\mathrm{W}$ since the power requirement of peripherals accounts for about half of the active-mode power requirements of minicomputers. Again, there is uncertainty in this estimate. 
Off Mode - Off mode for minicomputers describes machines that have useful life but are not plugged in, such as spares. Therefore we assumed the off-mode power requirement of minicomputers to be $0 \mathrm{~W}$.

\section{Notes on Displays}

Active Mode - According to LBNL measurements, the average power requirement of 17-inch displays is about $85 \mathrm{~W}$. According to Nordman et al. (1997), the power requirements of 15to 21 -inch displays range from $75 \mathrm{~W}$ to $120 \mathrm{~W}$. We assumed the average size of displays is 17 inches and thus estimated the average power requirement of displays at $85 \mathrm{~W}$.

The calculations above assume that all displays are cathode-ray tubes (CRTs), but, in actuality, the portion of displays that are liquid crystal displays (LCDs) is becoming significant. Because LCDs use considerably less energy than the same size CRT display (perhaps half as much on average) our estimate could be too high by this amount.

Low-Power Mode - According to EPA (2000), the average power requirement of new ENERGY STAR-compliant displays in low-power mode is $5 \mathrm{~W}$. According to Nordman et al. (1997), the average power requirement of displays in low-power mode is also $5 \mathrm{~W}$. We estimated the average power requirement of displays in low-power mode at $5 \mathrm{~W}$.

Off Mode - According to LBNL measurements, the power requirement of displays in off mode is about $0.3 \mathrm{~W}$. We estimated the average power requirement of displays in off mode at $0.5 \mathrm{~W}$.

\section{Notes on Terminals}

Active Mode - Since most terminals are 14- and 15-inch black-and-white terminals, we assumed that the average power requirement of terminals is same as that for 15-inch displays, or $75 \mathrm{~W}$.

Low-Power Mode - Because the standard low-power mode for ENERGY STAR is same for terminals and displays, we assumed that the average low-power mode for terminals is the same as that for displays, or $5 \mathrm{~W}$.

Off Mode - We assumed the average off-mode power requirement of terminals to be the same as that for displays, or $0.5 \mathrm{~W}$.

\section{Notes on Laser Printers}

Active Mode - For laser printers, power levels vary considerably by the capacity (images/minute) of the unit. We calculated a stock-weighted average across the power levels listed in Table A-5 to arrive at the levels used in our energy calculations. 
Table A-5. Average Power Requirements for Laser Printers in Active-Mode (LBNL)

\begin{tabular}{|lc|c|}
\hline Equipment Type & $\begin{array}{c}\text { Average Power Requirement } \\
\text { of Active Mode (W) }\end{array}$ \\
\hline Black \& White Laser Printer & $6-10 \mathrm{ppm}$ & $43 \mathrm{~W}$ \\
& $16-18 \mathrm{ppm}$ & $73 \mathrm{~W}$ \\
& $24-32 \mathrm{ppm}$ & $105 \mathrm{~W}$ \\
Color Laser Printer & & $150 \mathrm{~W}$ \\
\hline
\end{tabular}

Low-Power Mode - By calculating the stock-weighted average of the measured data in Table A-6, we estimated the average power requirement for residential and commercial/industrial stock of laser printers.

Table A-6. Average Power Requirements for Laser Printers in Low-Power Mode (EPA 2000)

\begin{tabular}{|ll|c|}
\hline Equipment Type & $\begin{array}{c}\text { Average Power Requirement } \\
\text { of Low-Power Mode }(W)\end{array}$ \\
\hline Black \& White Laser Printer & $\geq 8 \mathrm{ppm}$ & $25 \mathrm{~W}$ \\
& $<8 \mathrm{ppm}$ & $20 \mathrm{~W}$ \\
\hline
\end{tabular}

Off Mode - According to Meyer and Schaltegger (1999), the average power requirement for laser printers in off mode is $0.9 \mathrm{~W}$. We estimated the average power requirement for laser printers in off mode as $1.0 \mathrm{~W}$.

\section{Notes on Inkjet Printers}

Active Mode, Low-Power Mode - According to EPA (2000), the average active-mode power requirement of new ENERGY STAR-compliant inkjet printers is $17 \mathrm{~W}$. Because most new inkjet printers are compliant with ENERGY STAR and there has not been significant power reductions during the past several years (EPA 2000), we estimated the average active-mode power requirement of inkjet printers at $17 \mathrm{~W}$.

Because most inkjet printers do not have specific low-power operating modes, we did not make a separate estimation of energy use in low-power mode for this device.

Off Mode - According to Meyer and Schaltegger (1999), the average off-mode power requirement for inkjet printers is $2.8 \mathrm{~W}$. Based on measurements at LBNL, we estimated the average power requirement for inkjet printers in off mode at $2 \mathrm{~W}$.

\section{Notes on Copiers}

Active Mode, Low-Power Mode - According to Nordman et al. (1998), the average power requirements of active mode and low-power mode for each class of copiers are as shown in Table A-7. The average power requirement of low-power mode for low-speed copiers was estimated at $62 \mathrm{~W}$, assuming that is the same as the low-power standard of $20 \mathrm{cpm}$ ENERGY STAR copiers. By stock-weighting the average power requirement for each class of copiers, we estimated the average power requirements of commercial/industrial copiers in active mode and low-power mode at $183 \mathrm{~W}$ and $76 \mathrm{~W}$, respectively. Because all residential copiers 
are low-speed copiers, we estimated the average power requirement of residential copiers in active mode and low-power mode at $115 \mathrm{~W}$ and $62 \mathrm{~W}$, respectively.

Table A-7. Average Power Requirements for Copiers in Active and Low-Power Mode (Nordman et al. 1998)

\begin{tabular}{|lr|c|c|}
\hline \multicolumn{2}{|l|}{ Copier Type } & Active $(W)$ & Low-Power $(W)$ \\
\hline Low Speed $\quad<21 \mathrm{cpm}$ & 115 & N.A. \\
Mid Speed & $21-44 \mathrm{cpm}$ & 180 & 75 \\
High Speed $>44 \mathrm{cpm}$ & 290 & 97 \\
\hline
\end{tabular}

Off Mode - According to EPA (2000), the average off-mode power requirements of new ENERGY STAR-compliant copiers were estimated as shown in Table A-8. Since most new copiers are compliant with ENERGY STAR, we assumed the average power requirement of copiers in off mode is same as that for ENERGY STAR copiers. By stock-weighting the average power requirement of each class of copiers, we estimated the average power requirement of commercial/industrial copiers in off mode at $8.5 \mathrm{~W}$. Because all residential copiers are low-speed copiers, we estimated the average power requirement of residential copiers off mode at $1.4 \mathrm{~W}$.

Table A-8. Average Power Requirements of Copiers in Off Mode (EPA 2000)

\begin{tabular}{|lr|c|}
\hline Copier Type & Off $(W)$ \\
\hline Low Speed $\quad<21 \mathrm{cpm}$ & 1.4 \\
Mid Speed $21-44 \mathrm{cpm}$ & 14.1 \\
High Speed $\quad>44 \mathrm{cpm}$ & 11.4 \\
\hline
\end{tabular}

\section{Notes on Faxes}

Active Mode - Because most faxes do not have a specific low-power operating mode, we did not estimate power requirements for faxes in low-power mode separately. As shown in Table 2, we consider "ready/standby" mode as the active mode for faxes. "Send/receive" modes are ignored here because of the very small amount of time spent in those modes. According to EPA (2000), the average power requirement of new ENERGY STAR-compliant faxes in active mode is $11.2 \mathrm{~W}$. Because most new faxes are compliant with ENERGY STAR, we estimated the average power requirement of residential faxes in active mode at $10 \mathrm{~W}$ and that of commercial/industrial faxes at $15 \mathrm{~W}$.

\section{Power-Management (PM)-Enabled Rates of Office Equipment}

The PM-enabled rate is the percentage of equipment that have PM capabilities and whose PM is properly operating. Equipment that has PM capability but that has not been correctly enabled is not included in this category.

We estimated the rate for each type of equipment mainly based on the results of audits for nighttime status. We assumed that the PM-enabled rate is same for residential, commercial and industrial use.

The PM-enabled rate for each type of office equipment is shown in Table A-9. 
Table A-9. PM-Enabled Rates of Office Equipment

\begin{tabular}{|l|c|}
\hline Equipment Type & PM-Enabled Rate \\
\hline Desktop Computer & $25 \%$ \\
Portable Computer & $100 \%$ \\
Server Computer & $25 \%$ \\
Display/Terminal & $60 \%$ \\
Laser Printer only "low-power" is enabled & $80 \%$ \\
Copier "low-power" and "auto-off" are enabled & $34 \%$ \\
\multicolumn{2}{|c|}{} \\
\hline
\end{tabular}

\section{Notes on Desktop Computers}

According to Nordman et al. (2000), 25\% of desktop computers in offices have PM enabled.

\section{Notes on Portable Computers}

Because almost all portable computers have PM and have this feature enabled, we assumed that $100 \%$ of portable computers have PM enabled. Because this estimate is heavily dependent on assumptions, there is significant uncertainty.

\section{Notes on Server Computers}

We assumed the same PM-enabled rate for server computers as for desktop computers (25\%). Because this estimate is heavily dependent on assumptions, there are significant uncertainties.

\section{Notes on Displays and Terminals}

According to Nordman et al. (2000), $60 \%$ of displays in office have PM and have this feature enabled. We assumed that the PM-enabled rate for terminals is same as for displays.

\section{Notes on Laser Printers}

According to Nordman's unpublished 1999 survey, 83\% of ENERGY STAR-compliant laser printers in offices have PM enabled. Considering that most laser printers are ENERGY STARcompliant, we estimated the power-management-enabled rate at $80 \%$.

\section{Notes on Copiers}

According to Nordman et al. (1998), nighttime status for copiers in offices is as shown in Table A-10. According to Webber et al. (2000), 55\% of copiers are compliant with ENERGY STAR. Considering that $10 \%$ of copiers are turned off manually, we estimated that two thirds of the stock have low-power enabled and one third of the stock have auto-off enabled. We also assumed that all copiers that have auto-off enabled also have low-power enabled. 
Table A-10. Nighttime Status of Copiers (Nordman et al. 1998)

\begin{tabular}{|l|c|c|c|}
\hline Copier Type & Active & Low-Power & Manually Off or Auto-Off \\
\hline Conventional Copier & $30 \%$ & $53 \%$ & $17 \%$ \\
ENERGY STAR Copier & $27 \%$ & $12 \%$ & $61 \%$ \\
\hline
\end{tabular}

\section{Usage of Office Equipment}

General Methodology. We estimated the average usage (mode distribution over a week) for each type of office equipment. Low-power mode describes the case that equipment has PM capability and that PM is enabled. Several factors combine to determine the average mode distribution. Causative factors are the work habits of the machine's users, the configuration of PM features, and the extent to which equipment is turned off manually. We defined the following parameters that describe those factors: ${ }^{2}$

1. Daytime Length

Daytime = Average time during which equipment is used in a week (hours/week)

Nighttime = Average time during which equipment is not used in a week (hours/week)

2. Daytime status for PM-enabled machines

Day $_{\text {Active }}=$ Average rate of "active" during daytime $(\%)$

Day ${ }_{\text {Low }}=$ Average rate of "low-power" during daytime (\%)

Day ${ }_{\text {Off }}=$ Average rate of "off" during daytime (\%)

3. Nighttime Status - whether the equipment is on (active or low-power) or off during the night.

$\mathrm{Night}_{\text {On }}=$ Average rate of "on" during nighttime (\%)

Night ${ }_{\text {off }}=$ Average rate of "manually off" during nighttime (\%)

"Daytime" originally meant regular working hours for office workers. We expanded the meaning of "daytime" from the office work hours to the average time during which each type of office equipment is used. For example, we estimated "daytime" for commercial laser printers at 56 hours per week, which means about 11 hours per work day, because this equipment is usually shared and therefore used for longer than an individual's work day.

We also used "daytime" for residential equipment. We estimated "daytime" for residential laser printers at 3.5 hours/week, for example, which means people at home use their laser printers for an average of 3.5 hours per week. "Daytime" is different from the time during which machines are active. "Daytime" does not account for PM status or machines that are turned off. "Nighttime" is defined as the time not accounted for by "daytime".

Usage is estimated in the following way:

$$
\begin{aligned}
H A_{i} & =\text { Daytime }_{i} \times \text { Day }_{\text {Active }, i} \\
H L_{i} & =\text { Daytime }_{i} \times \text { Day }_{\text {Low }, i}+\text { Nighttime }_{i} \times \text { Night }_{\text {On }, i} \\
H O_{i} & =\text { Daytime }_{i} \times \text { Day }_{\text {Off }, i}+\text { Nighttime }_{i} \times \text { Night }_{\text {Off }, i}
\end{aligned}
$$

\footnotetext{
${ }^{2}$ For commercial and industrial use, these parameters were estimated mainly based on the results of power data logging and night audits.
} 
where

$H A_{i}=$ Hours of operation in active mode for equipment type $i$ (hours/week)

$H L_{i}=$ Hours of operation in low-power mode for equipment type $i$ (hours/week)

$\mathrm{HO}_{i}=$ Hours of operation in off mode for equipment type $i$ (hours/week).

We assumed there is no difference in usage between commercial and industrial equipment.

Results. Tables A-11 and A-12 show the best-guess estimates of average office equipment usage (hours/week) for each equipment type and power mode.

Table A-11. Residential Usage

\begin{tabular}{|l|c|c|c|c|}
\hline Equipment Type & $\begin{array}{c}\text { Active } \\
\text { (hr/week) }\end{array}$ & $\begin{array}{c}\text { Low-Power } \\
(\text { hr/week })\end{array}$ & $\begin{array}{c}\text { Off } \\
\text { (hr/week })\end{array}$ & $\begin{array}{c}\text { Disconnected } \\
\text { (hr/week) }\end{array}$ \\
\hline Portable Computer & 10 & 5 & 0 & 153 \\
Desktop Computer & 10 & 5 & 153 & 0 \\
Display & 10 & 5 & 153 & 0 \\
Laser Printer & 0.7 & 4.3 & 163 & 0 \\
Inkjet Printer Low-Power Enabled & 5 & $(*)$ & 163 & 0 \\
Copier Low-Power \& Auto-Off Enabled & 7 & 69 & 92 & 0 \\
Fax Lo & 134 & 20 & 141 & 0 \\
\hline
\end{tabular}

* We did not estimate use of low-power modes for inkjet printers and faxes.

Table A-12. Commercial and Industrial Usage

\begin{tabular}{|l|c|c|c|c|}
\hline Equipment Type & $\begin{array}{c}\text { Active } \\
(\text { hr/week })\end{array}$ & $\begin{array}{c}\text { Low-Power } \\
(\text { hr/week })\end{array}$ & $\begin{array}{c}\text { Off } \\
\text { (hr/week })\end{array}$ & $\begin{array}{c}\text { Disconnected } \\
(\text { hr/week })\end{array}$ \\
\hline Portable Computer & 19 & 61 & 0 & 88 \\
Desktop Computer & 19 & 61 & 88 & 0 \\
Server & 101 & 50 & 17 & 0 \\
Minicomputer & 74 & 76 & 18 & 0 \\
Mainframe & 74 & 76 & 18 & 0 \\
Display & 19 & 61 & 88 & 0 \\
Terminal Low-Power Enabled & 19 & 61 & 88 & 0 \\
Laser Printer & 11 & 118 & 39 & 0 \\
Inkjet Printer Auto-Off Enabled & 27 & $(*)$ & 97 & 0 \\
Copier & 150 & 113 & 28 & 0 \\
Fax Low-Power \& & 27 & 114 & 0 \\
\hline
\end{tabular}

* We did not estimate use of low-power modes for inkjet printers and faxes

\section{Notes on Commercial and Industrial Desktop Computers}

We estimated usage of commercial/industrial desktop computers based on the parameters in Table A-13. 
Table A-13. Parameters for Commercial and Industrial Usage of Desktop Computers

\begin{tabular}{|l|c|c|}
\hline Nighttime Status & On & $35 \%$ \\
& Off & $65 \%$ \\
\hline Daytime Status of PM-enabled Machines & Active & $40 \%$ \\
& Low-Power & $40 \%$ \\
& Off & $20 \%$ \\
\hline \multicolumn{2}{|l|}{ Daytime Length } & 48 hours/week \\
\hline
\end{tabular}

Nighttime Status - According to Nordman et al. (2000), 65\% of desktop computers are off at night.

Daytime Status of PM-enabled Machines - According to Newsham et al. (1994), about 20\% of desktop computers are off during the daytime. According to Szydlowski et al. (1994), desktop computers are active for $38 \%$ of the daytime and at low power for $62 \%$ of the daytime when the PM timer is set to 15 minutes. We believe that the rate of active-mode use has increased since 1994 because of the frequent access to the Internet, so we assumed that desktop computers are active for $40 \%$ of the daytime, at low power for $40 \%$, and off for $20 \%$.

Daytime Length - We used the same daytime lengths as used in Koomey et al. (1995).

\section{Notes on Residential Desktop Computers}

We estimated usage of residential desktop computers based on the parameters in Table A-14. Because these estimates are heavily dependent on assumptions, there are significant uncertainties.

Table A-14. Parameters for Residential Usage of Desktop Computers

\begin{tabular}{|l|c|c|}
\hline Nighttime Status & On & $3 \%$ \\
& Off & $97 \%$ \\
\hline Daytime Status of PM-enabled Machines & Active & $100 \%$ \\
& Low-Power & $0 \%$ \\
& Off & $0 \%$ \\
\hline Daytime Length & 10 hours/week \\
\hline
\end{tabular}

Nighttime Status - We assumed 3\% of all residential desktop computers are left "on" during the night.

Daytime Status of PM-enabled Machines - We assumed that residential desktop computers are always active during the daytime.

Daytime Length - According to CEMA (1998), residential desktop computers are used for an average of 10 hours per week.

\section{Notes on Portable Computers}

We assumed that the use of portable computers is same as the use of desktop computers except that portables are disconnected when off. Because our estimates are heavily dependent on assumptions, there are significant uncertainties. 


\section{Notes on Servers}

We estimated server usage based on the parameters in Table A-15.

Table A-15. Parameters for Usage of Servers

\begin{tabular}{|l|c|c|}
\hline Nighttime Status of PM-enabled Machines & Active & $45 \%$ \\
& Low-Power & $45 \%$ \\
& Off & $10 \%$ \\
\hline Daytime Status of PM-enabled Machines & Active & $90 \%$ \\
& Low-Power & $0 \%$ \\
& Off & $10 \%$ \\
\hline Daytime Length & 56 hours/week \\
\hline
\end{tabular}

We assumed that $10 \%$ of all servers are off, accounting for machines that are either not plugged in (spares) or not turned on. For servers without PM, we assumed the remaining $90 \%$ are always in active mode. For servers with PM, we were forced to consider nighttime active and low-power modes separately, since servers are used in network environments that sometimes provide nighttime services like monitoring and backups. We assumed that half of operating servers with $\mathrm{PM}$ are in low-power mode during nighttime and the other half are in active mode. Finally, we assumed the daytime length as 56 hours/week, which is longer than that for desktop computers because servers are generally shared. There are significant uncertainties in our estimates because of the heavy dependence on assumptions.

\section{Notes on Minicomputers and Mainframes}

We assumed the same mode distributions for minicomputers and mainframes as Koomey et al. (1995). Because the estimates are heavily dependent on assumptions, there are significant uncertainties.

\section{Notes on Displays and Terminals}

We assumed that the usage for displays and terminals is same as that for desktop computers.

\section{Notes on Commercial and Industrial Laser Printers}

We estimated the usage of commercial/industrial laser printers based on the parameters in Table 16.

Table A-16. Parameters for Commercial and Industrial Usage of Laser Printers

\begin{tabular}{|l|c|c|}
\hline Nighttime Status & On & $70 \%$ \\
& Off & $30 \%$ \\
\hline Daytime Status of PM-enabled Machines & Active & $20 \%$ \\
& Low-Power & $70 \%$ \\
& Off & $10 \%$ \\
\hline \multicolumn{2}{|l|}{ Daytime Length } & 56 hours/week \\
\hline
\end{tabular}

Nighttime Status. - According to Nordman's unpublished 1999 survey, 27\% of laser printers are off during the night. 
Daytime Status of PM-enabled Machines - According to Brown (2000), PM-enabled laser printers are ready for $21 \%$ of the daytime and at low power for $79 \%$ of the daytime. We assumed that $10 \%$ of laser printers are off during the daytime to account for machines that are turned off.

Daytime Length - We assumed laser printers are used for 56 hours per week, a longer period than that for desktop computers because laser printers are usually shared.

\section{Notes on Residential Laser Printers}

We estimated the usage of residential laser printers based on the parameters in Table 17. Because the estimates are heavily dependent on assumptions, there are significant uncertainties.

Table A-17. Parameters for Residential Usage of Laser Printers

\begin{tabular}{|l|c|c|}
\hline Nighttime Status & On & $1 \%$ \\
& Off & $99 \%$ \\
\hline Daytime Status of PM-enabled Machines & Active & $20 \%$ \\
& Low-Power & $80 \%$ \\
& Off & $0 \%$ \\
\hline Daytime Length & 3.5 hours/week \\
\hline
\end{tabular}

Nighttime Status - We assumed that $1 \%$ of all laser printers are left "on" during the night.

Daytime Status of PM-Enabled Machines - We assumed that laser printers are active for 20\% of the daytime and at low power for $80 \%$ of daytime.

Daytime Length - According to Meyer and Schaltegger (1999), residential laser printers are used 3.5 hours per week.

\section{Notes on Commercial and Industrial Inkjet Printers}

We estimated the usage of commercial/industrial inkjet printers based on the parameters in Table A-18. Because the estimates are heavily dependent on assumptions, there are significant uncertainties.

Table A-18. Parameters for Commercial and Industrial Usage of Inkjet Printers

\begin{tabular}{|l|c|c|}
\hline Nighttime Status & On & $35 \%$ \\
& Off & $65 \%$ \\
\hline Daytime Status & Active & $80 \%$ \\
& Off & $20 \%$ \\
\hline Daytime Length & 28 hours/week \\
\hline
\end{tabular}

Nighttime Status - We assumed the same usage of commercial/industrial inkjet printers as that for desktop computers, since both are usually used individually.

Daytime Status - We assumed that commercial/industrial inkjet printers are off during the daytime at the same rate as desktop computers, since both are usually used individually. 
Daytime Length - We assumed that inkjet printers are used 28 hours per week, which is half the amount of time that we assumed for laser printers since inkjet printers are generally not shared like laser printers and tend to be used by individuals. Moreover, many inkjet printers are portable inkjet printers, which are used intermittently by nature.

\section{Notes on Residential Inkjet Printers}

We estimated the usage of residential inkjet printers based on the parameters in Table A-19. Because the estimates are heavily dependent on assumptions, there are significant uncertainties.

Table A-19. Parameters for Residential Usage of Inkjet Printers

\begin{tabular}{|l|c|c|}
\hline Nighttime Status & On & $1 \%$ \\
& Off & $99 \%$ \\
\hline Daytime Status & Active & $100 \%$ \\
& Off & $0 \%$ \\
\hline Daytime Length & & 3.5 hours/week \\
\hline
\end{tabular}

Nighttime Status - We assumed that 1\% of all inkjet printers are left "on" during the night.

Daytime Status - We assumed that inkjet printers are always "on" during the daytime.

Daytime Length - According to Meyer and Schaltegger (1999), inkjet printers are used 3.5 hours per week.

\section{Notes on Commercial and Industrial Copiers}

We estimated the usage of commercial/industrial copiers based on the parameters in Table A-20.

Table A-20. Parameters for Commercial and Industrial Usage of Copiers

\begin{tabular}{|l|c|c|}
\hline Nighttime Status & On or Auto-Off & $80 \%$ \\
& Manual Off & $20 \%$ \\
\hline Daytime Status of Low-Power-Enabled & Active & $45 \%$ \\
Machines & Low-Power & $45 \%$ \\
& Off & $10 \%$ \\
\hline Daytime & 61 hours/week \\
\hline
\end{tabular}

Nighttime Status - According to Nordman et al. (1998), 16\% of copiers are off between 6 and 7 p.m. We believe that a few of those copiers were auto-off because 6-7 p.m seems early as an average end of the business day. We therefore assumed that $10 \%$ of copiers are turned off manually during the nighttime. Assuming that an additional $10 \%$ of copiers are off, to account for machines not in use, we then assumed that $20 \%$ of copiers are turned off manually during the night.

Daytime Status of Low-Power-Enabled Machines - We assumed slow-speed copiers $(<21 \mathrm{cpm})$ are in low-power mode for $75 \%$ of the daytime and active mode for $25 \%$ of the daytime. We assumed that mid-speed copiers (21-44 cpm) are in low-power mode for 50\% of the daytime and in active mode for $50 \%$ of the daytime. We assumed that high-speed copiers $(>44 \mathrm{cpm})$ are in low-power mode for $25 \%$ of the daytime and in active mode for $75 \%$ of the daytime. By taking a 
stock-weighted average, we estimated that copiers are in low-power mode for $50 \%$ of the daytime and in active mode for $50 \%$ of the daytime. We also assumed that no copiers are autooff during the daytime and that $10 \%$ of all copiers are turned off manually during the daytime.

Daytime Length - We assumed that commercial and industrial copiers are used for 61 hours per week on average. The daytime length assumed for copiers is higher than that for laser printers based on the assumption that the delay times associated with copiers are longer than those associated with laser printers.

\section{Notes on Residential Usage of Copiers}

We estimated the usage of residential copiers based on the parameters in Table A-21. Because the estimates are heavily dependent on assumptions, there are significant uncertainties.

Table A-21. Parameters for Residential Usage of Copiers

\begin{tabular}{|l|c|c|}
\hline Nighttime Status & On or Auto-Off & $35 \%$ \\
& Manual-Off & $65 \%$ \\
\hline Daytime Status for Low-Power-Enabled Machines & Active & $23 \%$ \\
& Low-Power & $68 \%$ \\
& Off & $10 \%$ \\
\hline \multicolumn{2}{|l|}{} & 30 hours/week \\
\hline
\end{tabular}

Nighttime Status - We assumed the same nighttime status for residential copiers as for commercial desktop computers because residential copiers are generally used for business purposes and are not shared.

Daytime Status of Low-Power-Enabled Machines - We assumed that slow-speed copiers $(\leq 20$ $\mathrm{cpm}$ ) are in low-power mode for $75 \%$ of the daytime and in active mode for $25 \%$ of the daytime. We also assumed that no copiers are auto-off during the daytime but that $10 \%$ of residential copiers are turned off manually during the daytime.

Daytime Length - We assumed that residential copiers are used 30 hours per week, which is half of the daytime length for commercial copiers, because residential copiers are generally not shared like commercial copiers.

\section{Notes on Commercial and Industrial Usage of Faxes}

We assumed that all faxes are always "on" when in use. We also assumed that $10 \%$ of commercial/industrial faxes are not installed.

\section{Notes on Residential Usage of Faxes}

We assumed that $20 \%$ of residential faxes are off. We also assumed that all faxes are always "on" when in use.

\section{Extra Energy Use for Printing or Copying}

General Methodology. Extra energy use for printing or copying is the energy required for these 
tasks beyond the energy used in active mode. We estimated extra energy use by combining the average unit paper consumption, the rate of two-sided printing or copying (duplexing rate), and the extra energy use for each image using the following equation:

$E P C_{i}=\left(U P C_{i} /\left(1-D U P_{i} \times 0.5\right)\right) \times E I_{i} / 1000$

where

$E P C_{i}=$ Extra energy for printing or copying for equipment type $i(\mathrm{kWh} / \mathrm{year})$

$U P C_{i}=$ Unit paper consumption for equipment type $i$ (sheets/year)

$D U P_{i}=$ Duplexing rate, fraction of images placed onto duplexed sheets, for equipment type $i(\%)$

$E I_{i}=$ Extra energy for each image for equipment type $i$ (W/image)

Because most assumptions are based on data cited from other papers or on our own judgments, there are uncertainties in these estimates. However, total paper consumption is well known and as such limits the inaccuracies in our conclusions about total energy consumption for printing or copying.

Typical imaging and paper use rates are not well-documented. Printers and copiers are rated for their maximum monthly imaging rates, and actual use is typically much less than this (e.g., one source estimates that copiers are typically used at about $15 \%$ of their rated capacity). Most analyses of imaging energy and paper use begin with the total amount of paper used and then allocate this total based on professional judgment and anecdotal data on typical imaging and paper use rates. We use this approach, relying on a mixture of data cited from others and our own judgment. We estimate the amount of paper likely to be used in homes and subtract this from the total to get commercial and industrial use. We assumed that commercial and industrial UPC are same.

Duplexing Rate. The duplexing rate represents the fraction of all images placed onto two-sided, or "duplexed", sheets. A $100 \%$ duplexing rate requires half as much paper as a $0 \%$ duplexing rate.

According to Graff and Fishbein (1995), duplexing rates for copiers are estimated as shown in Table A-22. We estimated the duplexing rate for residential and commercial/industrial copiers by calculating a stock-weighted average duplexing rate for each class of copiers. We assumed that the duplexing rate for laser printers is same as that for copiers. We ignored duplexing for faxes and inkjet printers, because their duplexing rates appear to be much smaller than the rates for copiers. Table A-23 shows the duplexing rates for each type of office equipment. 
Table A-22. Duplexing Rate of Copiers (Graff and Fishbein 1995)

\begin{tabular}{|l|c|c|c|}
\hline Copier Speed (cpm) & $\begin{array}{c}\text { 1998 Stock } \\
\text { (thousands) }\end{array}$ & $\begin{array}{c}\text { Annual Copied Sheets/Unit } \\
\text { (thousands) }\end{array}$ & $\begin{array}{c}\text { Duplexing Rate } \\
(\%)\end{array}$ \\
\hline$<10$ & 2,893 & 1 & $0 \%$ \\
$10-19$ & 1,875 & 25 & $2 \%$ \\
$20-30$ & 1,128 & 66 & $8 \%$ \\
$31-45$ & 694 & 111 & $14 \%$ \\
$46-69$ & 850 & 141 & $22 \%$ \\
$70-90$ & 215 & 465 & $40 \%$ \\
$91-$ & 86 & 1,620 & $60 \%$ \\
\hline
\end{tabular}

Table A-23. Duplexing Rate of Each Type of Office Equipment

\begin{tabular}{|l|c|c|}
\hline Equipment Type & Residential & Commercial/Industrial \\
\hline Copier & $2 \%$ & $30 \%$ \\
Laser Printer & $2 \%$ & $30 \%$ \\
Inkjet Printer & $0 \%$ & $0 \%$ \\
Fax & $0 \%$ & $0 \%$ \\
\hline
\end{tabular}

Unit Paper Consumption (UPC) for Residential Office Equipment. We assumed that the amount of copier paper consumed by a residential copier is the same as that consumed by an average low-speed copier, which is about 10,000 sheets/year. We assumed that the annual paper consumption of an inkjet printer or fax is 300 sheets/year, since most of these machines are for home use.

According to DOE (1999), about 15\% of all households with PCs used these machines for business as well as private purposes. Drawing from this fact, it is natural to assume that more than $15 \%$ of residential laser printers are used for business as well as private purposes. We assumed that $25 \%$ of residential laser printers are for business as well as private use and that they consume 5,000 sheets/year. We also assumed that $75 \%$ of residential laser printers are only for private use and consume 300 sheets/year. Finally, by calculating stock-weighted averages, we estimated the UPC for residential laser printers at 1,475 sheets/year.

Table A-24 shows the UPC for each type of office equipment.

Table A-24. Unit Paper Consumption of Residential Office Equipment

\begin{tabular}{|l|c|}
\hline Equipment Type & UPC (sheets/year) \\
\hline Copier & 10,000 \\
Laser Printer & 1,475 \\
Inkjet Printer & 300 \\
Fax & 300 \\
\hline
\end{tabular}

Unit Paper Consumption (UPC) for Commercial and Industrial Office Equipment. To estimate UPC for commercial/industrial equipment, we first estimated the total weight of paper consumed by all office equipment based on data from Pulp \& Paper (1995). Second, by assuming the weight of paper is 5 grams/sheet, we estimated the total number of sheets consumed by office equipment at 840 billion sheets/year (4.2 million tons/year). Third, we allocated $45 \%$ of total paper consumed to copiers, another $45 \%$ to laser printers, $5 \%$ to inkjet printers, and another $5 \%$ to faxes. Fourth, by subtracting our estimate of residential paper consumption, we estimated commercial and industrial paper consumption for each type of office equipment. Finally, by 
dividing total paper consumption by the stock, we estimated the UPC for each type of office equipment.

Table A-25 shows the UPC for each type of equipment.

Table A-25. Unit Paper Consumption of Commercial and Industrial Office Equipment

\begin{tabular}{|l|c|}
\hline Equipment Type & UPC (sheets/year) \\
\hline Copier & 45,590 \\
Laser Printer & 17,000 \\
Inkjet Printer & 1,130 \\
Fax & 1,853 \\
\hline
\end{tabular}

Extra Energy for Each Image. According to Nordman et al. (1998), the extra energy used for each image made by copiers is about 1 Wh. According to Brown et al. (2000), the extra energy used for each image produced by laser printers is also about $1 \mathrm{Wh}$. Since most images are produced by copiers or laser printers, we assumed that the extra energy for each image is $1 \mathrm{Wh}$ for all types of equipment.

Results. Table A-26 shows the extra energy used for printing or copying by each type of equipment.

Table A-26. Extra Energy for Printing or Copying (kWh/year)

\begin{tabular}{|l|c|c|}
\hline Equipment Type & Residential & Commercial and Industrial \\
\hline Copier & 10.1 & 53.6 \\
Laser Printer & 1.5 & 20.0 \\
Inkjet Printer & 0.3 & 1.1 \\
Fax & 0.3 & 1.9 \\
\hline
\end{tabular}

\section{Uncertainty Analysis}

Uncertainty in the Input Data. We estimated the uncertainty in each type of input data based on the quality or origin of the data. We did not separately estimate uncertainty in commercial input data and industrial input data.

Tables A-27 and A-28 show our estimates of the range of uncertainty in commercial/industrial and residential input data, respectively. We show our best-guess estimate and our low and high estimates for each parameter. These intervals are not confidence intervals in the formal sense, though they do give a rough idea of the potential uncertainty in each input parameter. We make no claims about the shape of the distribution of this uncertainty, just the absolute range.

We carry through the calculations, changing each parameter individually to its low or high value to determine the effect of such changes on the final estimate of electricity use, in GWh/year. The results of these calculations are shown in Tables A-29 and A-30 (below). 
Table A-27. Uncertainty in Commercial and Industrial Office Equipment Input Data

\begin{tabular}{|c|c|c|c|c|c|c|c|c|}
\hline \multirow{2}{*}{$\begin{array}{l}\text { Equipment } \\
\text { Type }\end{array}$} & & \multirow{2}{*}{$\begin{array}{c}\text { Stock } \\
\text { (thousand) }\end{array}$} & \multicolumn{3}{|c|}{ Power Requirement $(W)$} & \multirow{2}{*}{$\begin{array}{l}\text { Usage (hour/week) } \\
\text { Active / Low / Off }\end{array}$} & \multirow{2}{*}{$\begin{array}{c}S P M^{*} \\
(\%)\end{array}$} & \multirow{2}{*}{$\begin{array}{r}E P C * * \\
(k W h / y r)\end{array}$} \\
\hline & & & Active & Low & Off & & & \\
\hline $\begin{array}{l}\text { Portable } \\
\text { Computer }\end{array}$ & $\begin{array}{l}\text { Best Estimate } \\
\text { Highest Estimate } \\
\text { Lowest Estimate }\end{array}$ & $\begin{array}{l}6,060 \\
8,190 \\
3,460\end{array}$ & $\begin{array}{c}15 \\
18 \\
13.5\end{array}$ & $\begin{array}{c}3 \\
4 \\
2.5\end{array}$ & $\begin{array}{c}2 \\
2.5 \\
1.5\end{array}$ & $\begin{array}{c}19 / 61 / 0 \\
21 / 67 / 40 \\
17 / 55 / 0\end{array}$ & $\begin{array}{c}100 \\
100 \\
80\end{array}$ & $\begin{array}{l}0 \\
0 \\
0\end{array}$ \\
\hline $\begin{array}{l}\text { Desktop } \\
\text { Computer }\end{array}$ & $\begin{array}{l}\text { Best Estimate } \\
\text { Highest Estimate } \\
\text { Lowest Estimate }\end{array}$ & $\begin{array}{l}54,580 \\
63,630 \\
43,880 \\
\end{array}$ & $\begin{array}{c}55 \\
57.5 \\
50\end{array}$ & $\begin{array}{c}25 \\
27.5 \\
22.5\end{array}$ & $\begin{array}{c}1.5 \\
2 \\
1\end{array}$ & $\begin{array}{l}19 / 61 / 88 \\
21 / 67 / 80 \\
17 / 55 / 96\end{array}$ & $\begin{array}{l}25 \\
30 \\
20\end{array}$ & $\begin{array}{l}0 \\
0 \\
0\end{array}$ \\
\hline Server & $\begin{array}{l}\text { Best Estimate } \\
\text { Highest Estimate } \\
\text { Lowest Estimate }\end{array}$ & $\begin{array}{l}3,330 \\
4,300 \\
2,320\end{array}$ & $\begin{array}{l}75 \\
90 \\
60\end{array}$ & $\begin{array}{c}25 \\
30 \\
22.5\end{array}$ & $\begin{array}{l}1.5 \\
2 \\
1\end{array}$ & $\begin{array}{c}101 / 50 / 17 \\
119 / 32 / 17 \\
81 / 70 / 17\end{array}$ & $\begin{array}{l}25 \\
30 \\
15\end{array}$ & $\begin{array}{l}0 \\
0 \\
0\end{array}$ \\
\hline $\begin{array}{l}\text { Mini } \\
\text { Computer }\end{array}$ & $\begin{array}{l}\text { Best Estimate } \\
\text { Highest Estimate } \\
\text { Lowest Estimate }\end{array}$ & $\begin{array}{l}2,020 \\
2,260 \\
1,540\end{array}$ & $\begin{array}{c}1,000 \\
1,100 \\
700\end{array}$ & $\begin{array}{l}500 \\
550 \\
350\end{array}$ & $\begin{array}{l}0 \\
0 \\
0\end{array}$ & $\begin{array}{l}74 / 76 / 18 \\
94 / 65 / 9 \\
64 / 77 / 27\end{array}$ & (B) & $\begin{array}{l}0 \\
0 \\
0\end{array}$ \\
\hline Mainframe & $\begin{array}{l}\text { Best Estimate } \\
\text { Highest Estimate } \\
\text { Lowest Estimate }\end{array}$ & $\begin{array}{c}107 \\
119 \\
83 \\
\end{array}$ & $\begin{array}{c}10,000 \\
11,000 \\
7,000 \\
\end{array}$ & $\begin{array}{l}5,000 \\
5,500 \\
3,500 \\
\end{array}$ & $\begin{array}{l}0 \\
0 \\
0 \\
\end{array}$ & $\begin{array}{c}74 / 76 / 18 \\
94 / 65 / 9 \\
64 / 77 / 27 \\
\end{array}$ & (B) & $\begin{array}{l}0 \\
0 \\
0 \\
\end{array}$ \\
\hline Display & $\begin{array}{l}\text { Best Estimate } \\
\text { Highest Estimate } \\
\text { Lowest Estimate }\end{array}$ & $\begin{array}{l}54,580 \\
63,630 \\
43,880 \\
\end{array}$ & $\begin{array}{l}85 \\
90 \\
80 \\
\end{array}$ & $\begin{array}{c}5 \\
5.5 \\
4.5 \\
\end{array}$ & $\begin{array}{l}0.5 \\
0.75 \\
0.25 \\
\end{array}$ & $\begin{array}{l}19 / 61 / 88 \\
21 / 67 / 80 \\
17 / 55 / 96 \\
\end{array}$ & $\begin{array}{l}60 \\
65 \\
55 \\
\end{array}$ & $\begin{array}{l}0 \\
0 \\
0 \\
\end{array}$ \\
\hline Terminal & $\begin{array}{l}\text { Best Estimate } \\
\text { Highest Estimate } \\
\text { Lowest Estimate }\end{array}$ & $\begin{array}{l}13,330 \\
16,680 \\
10,030 \\
\end{array}$ & $\begin{array}{l}75 \\
80 \\
70 \\
\end{array}$ & $\begin{array}{c}5 \\
5.5 \\
4.5 \\
\end{array}$ & $\begin{array}{l}0.5 \\
0.75 \\
0.25 \\
\end{array}$ & $\begin{array}{c}19 / 61 / 88 \\
21 / 79 / 68 \\
17 / 42 / 109 \\
\end{array}$ & $\begin{array}{r}60 \\
70 \\
50 \\
\end{array}$ & $\begin{array}{l}0 \\
0 \\
0\end{array}$ \\
\hline $\begin{array}{l}\text { Laser } \\
\text { Printer }\end{array}$ & $\begin{array}{l}\text { Best Estimate } \\
\text { Highest Estimate } \\
\text { Lowest Estimate }\end{array}$ & $\begin{array}{l}21,690 \\
25,040 \\
17,480 \\
\end{array}$ & $\begin{array}{l}77 \\
82 \\
72 \\
\end{array}$ & $\begin{array}{c}25 \\
27.5 \\
22.5 \\
\end{array}$ & $\begin{array}{c}1 \\
1.5 \\
0.5 \\
\end{array}$ & $\begin{array}{l}11 / 118 / 39 \\
12 / 121 / 35 \\
10 / 114 / 44 \\
\end{array}$ & $\begin{array}{l}80 \\
85 \\
75 \\
\end{array}$ & $\begin{array}{l}20 \\
24 \\
16 \\
\end{array}$ \\
\hline $\begin{array}{l}\text { Inkjet } \\
\text { Printer }\end{array}$ & $\begin{array}{l}\text { Best Estimate } \\
\text { Highest Estimate } \\
\text { Lowest Estimate }\end{array}$ & $\begin{array}{l}23,870 \\
27,370 \\
18,120 \\
\end{array}$ & $\begin{array}{l}17 \\
20 \\
15 \\
\end{array}$ & (A) & $\begin{array}{c}2 \\
2.5 \\
1.5 \\
\end{array}$ & $\begin{array}{c}71 /(\mathrm{A}) / 97 \\
82 /(\mathrm{A}) / 86 \\
37 /(\mathrm{A}) / 131 \\
\end{array}$ & (A) & $\begin{array}{l}1.1 \\
1.3 \\
0.9 \\
\end{array}$ \\
\hline Copier & $\begin{array}{l}\text { Best Estimate } \\
\text { Highest Estimate } \\
\text { Lowest Estimate }\end{array}$ & $\begin{array}{l}7,460 \\
8,980 \\
5,830 \\
\end{array}$ & $\begin{array}{l}183 \\
193 \\
173 \\
\end{array}$ & $\begin{array}{l}76 \\
80 \\
72 \\
\end{array}$ & $\begin{array}{l}8.5 \\
9.0 \\
8.0\end{array}$ & $\begin{array}{l}27 / 27 / 114 \\
30 / 30 / 108 \\
25 / 25 / 118 \\
\end{array}$ & $\begin{array}{l}34(\mathrm{C}) \\
39(\mathrm{C}) \\
29(\mathrm{C}) \\
\end{array}$ & $\begin{array}{l}53.6 \\
63.6 \\
43.6 \\
\end{array}$ \\
\hline Fax & $\begin{array}{l}\text { Best Estimate } \\
\text { Highest Estimate } \\
\text { Lowest Estimate }\end{array}$ & $\begin{array}{l}21,650 \\
24,040 \\
19,120\end{array}$ & $\begin{array}{c}15 \\
18 \\
13.5\end{array}$ & (A) & $\begin{array}{l}0 \\
0 \\
0\end{array}$ & $\begin{array}{c}150 / \text { (A) / } 18 \\
159 / \text { (A) / } 9 \\
141 / \text { (A) / } 27\end{array}$ & (A) & $\begin{array}{l}1.9 \\
2.3 \\
1.5\end{array}$ \\
\hline
\end{tabular}

*SPM $=$ Power management enabled rate (\%)

$* *$ EPC $=$ Extra energy used for printing or copying $(\mathrm{kWh} /$ year $)$

(A) We did not estimate low-power mode for inkjet printers and faxes.

(B) We did not estimate power management modes for minicomputers and mainframes. Low-power modes of minicomputers and mainframes do not mean power management but rather that peripherals are off while CPUs are on.

(C) We only considered the rate of auto-off enabling for copiers because the uncertainty in the rate of auto-off enabled causes more inaccuracies in the result than does the uncertainty in the rate of low-power enabling. 
Table A-28. Uncertainty in Residential Office Equipment Input Data

\begin{tabular}{|c|c|c|c|c|c|c|c|c|}
\hline \multirow{2}{*}{$\begin{array}{l}\text { Equipment } \\
\text { Type }\end{array}$} & & \multirow{2}{*}{$\begin{array}{c}\text { Stock } \\
\text { (thousand) }\end{array}$} & \multicolumn{3}{|c|}{ Power Requirement (W) } & \multirow{2}{*}{$\begin{array}{l}\text { Usage (hour/week) } \\
\text { Active / Low /Off }\end{array}$} & \multirow{2}{*}{$\begin{array}{c}S P M^{*} \\
(\%)\end{array}$} & \multirow{2}{*}{$\begin{array}{c}E P C^{* * *} \\
(k W h / y r)\end{array}$} \\
\hline & & & Active & Low & Off & & & \\
\hline \multirow{3}{*}{$\begin{array}{l}\text { Portable } \\
\text { Computer }\end{array}$} & Best Estimate & 16,090 & 15 & 3 & 2 & $10 / 5 / 0$ & 100 & 0 \\
\hline & Highest Estimate & 16,890 & 18 & 4 & 2.5 & $15 / 8 / 72$ & 100 & 0 \\
\hline & Lowest Estimate & 14,490 & 13.5 & 2.5 & 1.5 & $9 / 3 / 0$ & 80 & 0 \\
\hline \multirow{3}{*}{$\begin{array}{l}\text { Desktop } \\
\text { Computer }\end{array}$} & Best Estimate & 54,530 & 50 & 25 & 1.5 & $10 / 5 / 153$ & 25 & 0 \\
\hline & Highest Estimate & 57,260 & 52.5 & 27.5 & 2 & $15 / 8 / 145$ & 30 & 0 \\
\hline & Lowest Estimate & 49,080 & 47.5 & 22.5 & 1 & $9 / 3 / 156$ & 20 & 0 \\
\hline \multirow[t]{3}{*}{ Display } & Best Estimate & 54,530 & 85 & 5 & 0.5 & $10 / 5 / 153$ & 60 & 0 \\
\hline & Highest Estimate & 57,260 & 90 & 5.5 & 0.75 & $15 / 8 / 145$ & 65 & 0 \\
\hline & Lowest Estimate & 49,080 & 80 & 4.5 & 0.25 & $9 / 3 / 156$ & 55 & 0 \\
\hline \multirow{3}{*}{$\begin{array}{l}\text { Laser } \\
\text { Printer }\end{array}$} & Best Estimate & 6,300 & 30 & 20 & 1 & $0.7 / 4.3 / 163$ & 80 & 1.5 \\
\hline & Highest Estimate & 7,560 & 33 & 22 & 1.5 & $1 / 9 / 158$ & 85 & 1.8 \\
\hline & Lowest Estimate & 5,040 & 27 & 18 & 0.5 & $0.5 / 4 / 163.5$ & 75 & 1.2 \\
\hline \multirow{3}{*}{$\begin{array}{l}\text { Inkjet } \\
\text { Printer }\end{array}$} & Best Estimate & 50,200 & 17 & (A) & 2 & $5 /(\mathrm{A}) / 163$ & (A) & 0.3 \\
\hline & Highest Estimate & 60,240 & 20 & & 2.5 & $10 /(\mathrm{A}) / 158$ & & 0.4 \\
\hline & Lowest Estimate & 40,160 & 15 & & 1.5 & $4.5 /$ (A) / 163.5 & & 0.2 \\
\hline \multirow[t]{3}{*}{ Copier } & Best Estimate & 3,800 & 115 & 62 & 1.5 & $7 / 20 / 141$ & $34(\mathrm{~B})$ & 10 \\
\hline & Highest Estimate & 4,180 & 120 & 65 & 2 & $9 / 27 / 132$ & 39 (B) & 12 \\
\hline & Lowest Estimate & 3,420 & 110 & 59 & 1 & $5 / 14 / 149$ & 29 (B) & 8 \\
\hline \multirow[t]{3}{*}{ Fax } & Best Estimate & 6,300 & 10 & (A) & 0 & $134 /(\mathrm{A}) / 34$ & (A) & 0.3 \\
\hline & Highest Estimate & 6,930 & 12 & & 0 & $150 /(\mathrm{A}) / 18$ & & 0.4 \\
\hline & Lowest Estimate & 5,670 & 9 & & 0 & $127 /$ (A) / 41 & & 0.2 \\
\hline
\end{tabular}

*SPM $=$ Power-management-enabled rate $(\%)$

$* * \mathrm{EPC}=$ Extra energy used for printing or copying $(\mathrm{kWh} / \mathrm{year})$

(A) We did not estimate low-power modes for inkjet printers and faxes.

(B) We only considered the rate of auto-off mode for copiers because the uncertainty in auto-off enabling rates causes more inaccuracy in the result than is caused by the uncertainty in low-power enabling rates.

\section{Notes on Uncertainty in Commercial and Industrial Stocks}

The accuracy of commercial and industrial stock estimates depends on the accuracy of assumptions about equipment lifetimes. We assumed that the uncertainty in the estimates of lifetime for each equipment type as follows:

\begin{tabular}{|l|c|}
\hline Equipment Type & Uncertainty \\
\hline $\begin{array}{l}\text { Portable Computer, Desktop Computer, Server } \\
\text { Display, Terminal }\end{array}$ & 0.50 year \\
\hline Laser Printer, Inkjet Printer, Copier, Fax & 0.75 year \\
\hline Minicomputer, Mainframe & 2 years \\
\hline
\end{tabular}

\section{Notes on Uncertainty in Commercial and Industrial Power Requirements}

When our power-requirement estimates are based mainly on measured data, we assumed that the uncertainty rate in those estimates range from 5 to $10 \%$. When our estimates are based mainly on assumptions, we assumed that the uncertainty rate is 20 to $30 \%$.

\section{Notes on Uncertainty in Commercial and Industrial Usage (Mode Distributions)}

Equipment usage is calculated by combining the nighttime status, daytime status, and daytime length. Uncertainty in the daytime status estimates is much lower than the uncertainty associated with the other usage factors, so we did not include daytime status in our total uncertainty estimate. We calculated the uncertainty in usage by combining the uncertainty of the nighttime off-mode rate and daytime length. 
We assumed that the uncertainty in daytime length is 5 hours/week for all types of equipment except minicomputers, mainframes, and inkjet printers. We assumed that the uncertainty in daytime length is between 10 and 20 hours/week for minicomputers, mainframes, and inkjet printers.

We assumed that the uncertainty in nighttime off-mode rate is $5 \%$ or less (relative to the assumed rate) for all types of equipment except portable computers, terminals, and inkjet printers. For portable computers, terminals, and inkjet printers, we assumed that the uncertainty in the nighttime off-mode rate is between 10 and $30 \%$.

\section{Notes on Uncertainty in Commercial and Industrial PM-Enabled Rates}

We assumed that the uncertainty in the PM-enabled rate is 5\% for all types of equipment except portable computers and terminals. For portable computers and terminals, we assumed that the uncertainty is between 10 and $20 \%$.

\section{Notes on Uncertainty in Commercial and Industrial Energy Use for Printing or Copying}

We assumed that the uncertainty in extra energy used for printing or copying is $20 \%$.

\section{Notes on Uncertainty in Residential Stocks}

We assumed that the uncertainty rate of the residential stock estimates is $10 \%$ for all type of equipment except laser printers and inkjet printers. We assumed the uncertainty rate for laser printers and inkjet printers to be $20 \%$.

\section{Notes on Uncertainty in Residential Power Requirements}

When our estimates are based mainly on measured data, we assumed that the uncertainty rate in power requirements is between 5 and $10 \%$. When our estimates are based mainly on assumptions, we assumed that the uncertainty rate is between 20 and $30 \%$.

\section{Notes on Uncertainty in Residential Usage (Mode Distributions)}

Equipment usage is calculated by combining the nighttime status, daytime status, and daytime length. Uncertainty in the daytime status estimates is much lower than the uncertainty associated with the other usage factors, so we did not include daytime status in our total uncertainty estimate. We calculated the uncertainty in usage by combining the uncertainty of the nighttime off-mode rate and daytime length.

We assumed that the uncertainty in daytime length is around five hours/week for all types of equipment.

We assumed that the uncertainty in nighttime off-mode rates is around 3\% for all types of equipment.

Sensitivity Analysis. We conducted sensitivity analysis for the uncertainty associated with each 
input data category to evaluate the potential error in energy use calculations caused by each uncertainty. Tables A-29 and A-30 show the results of sensitivity analysis for uncertainty in commercial/industrial and residential input data, respectively.

Table A-29. Sensitivity Analysis of Uncertainty in Commercial/Industrial Office Equipment Input Data (GWh/year)

\begin{tabular}{|c|c|c|c|c|c|c|c|}
\hline \multirow[t]{2}{*}{ Equipment Type } & \multirow[t]{2}{*}{ Stock } & \multicolumn{3}{|c|}{ Power Requirement } & \multirow[t]{2}{*}{ Usage } & \multirow[t]{2}{*}{$S P M$} & \multirow[t]{2}{*}{$E P C$} \\
\hline & & Active & Low & Off & & & \\
\hline Portable Computer & $-64 /+52$ & $-9 /+18$ & $-10 /+19$ & 0 & $-15 /+40$ & +46 & 0 \\
\hline Desktop Computer & $-2285 /+1931$ & $-927 /+463$ & $-109 /+109$ & $-125 /+125$ & $-1033 /+1033$ & $-262 /+262$ & 0 \\
\hline Server & $-565 /+543$ & $-361 /+361$ & $-5 /+11$ & $-1 /+1$ & $-45 /+37$ & $-22 / 43$ & 0 \\
\hline Mini Computer & $-2815 /+1390$ & $-2341 /+780$ & $-1200 /+400$ & 0 & $-1001 /+1528$ & (B) & 0 \\
\hline Mainframe & $-1402 /+700$ & $-1239 /+413$ & $-636 /+212$ & 0 & $-530 /+809$ & (B) & 0 \\
\hline Display & $-2199 /+1859$ & $-621 /+621$ & $-52 /+52$ & $-62 /+62$ & $-1259 /+1259$ & $-697 /+697$ & 0 \\
\hline Terminal & $-603 /+612$ & $-151 /+151$ & $-12 /+12$ & $-15 /+15$ & $-505 /+505$ & $-298 /+298$ & 0 \\
\hline Laser Printer & $-1189 /+947$ & $-195 /+195$ & $-302 /+302$ & $-22 /+22$ & $-241 /+241$ & $-348 /+348$ & $-87 /+87$ \\
\hline Inkjet Printer & $-429 /+260$ & $-178 /+266$ & (A) & $-60 /+60$ & $-634 /+198$ & (A) & $-4 /+4$ \\
\hline Copier & $-1424 /+1330$ & $-246 /+246$ & $-81 /+81$ & $-10 /+10$ & $-263 /+273$ & $-112 /+112$ & $-74 /+74$ \\
\hline Fax & $-302 /+285$ & $-254 /+508$ & (A) & 0 & $-152 /+152$ & (A) & $-10 /+10$ \\
\hline
\end{tabular}

(A) We did not estimate low-power modes for inkjet printers and faxes.

(B) We did not estimate power management mode for minicomputers and mainframes. Low-power modes of minicomputers and mainframes do not imply power management but rather that peripherals are turned off while CPUs are on.

Table A-30. Sensitivity Analysis of Uncertainty in Residential Office Equipment Input Data (GWh/year)

\begin{tabular}{|l|c|c|c|c|c|c|c|}
\hline \multirow{2}{*}{ Equipment Type } & \multirow{2}{*}{ Stock } & \multicolumn{3}{|c|}{ Power Requirement } & Usage & \multirow{2}{*}{ SPM } & \multirow{2}{*}{ EPC } \\
\cline { 3 - 7 } & & Active & Low & Off & & & \\
\hline Portable Computer & $-14 /+7$ & $-12.5 /+25$ & $-2 /+4$ & 0 & $-17 /+192$ & +9 & 0 \\
Desktop Computer & $-267 /+133$ & $-96 /+96$ & $-8 /+8$ & $-217 /+217$ & $-347 /+1081$ & $-17 /+17$ & 0 \\
Display & $-313 /+157$ & $-169 /+169$ & $-4 /+4$ & $-109 /+109$ & $-421 /+1539$ & $-54 /+54$ & 0 \\
Laser Printer & $-20 /+20$ & $-1 /+1$ & $-2 /+2$ & $-27 /+27$ & $-5 /+35$ & $-1 /+1$ & $-2 /+2$ \\
Inkjet Printer & $-219 /+219$ & $-27 /+40$ & (A) & $-213 /+213$ & $-26 /+190$ & (A) & $-5 /+5$ \\
Copier & $-109 /+109$ & $-28 /+28$ & $-18 /+18$ & $-11 /+11$ & $-365 /+331$ & $-29 /+29$ & $-7 /+7$ \\
Fax & $-44 /+44$ & $-44 /+88$ & (A) & 0 & $-26 /+52$ & (A) & $-1 /+1$ \\
\hline
\end{tabular}

(A) We did not estimate low-power modes for inkjet printers and faxes.

Findings. Generally, the uncertainty in commercial/industrial input data causes much larger errors in energy use calculations (in absolute terms) than the uncertainty in residential input data. For residential input data, uncertainty in the usage estimates for desktop computers and displays are the only items that cause more than $1,000 \mathrm{GWh} /$ year error in the energy use calculations, while uncertainty in usage of copiers is the only one with an absolute value between 500 and $1,000 \mathrm{GWh} /$ year. The other uncertainties for residential equipment all have an absolute value that is less than $500 \mathrm{GWh}$ per year.

Table A-31 shows the classification of commercial/industrial input data according to the level of error in energy use caused by the respective uncertainty. In this table, we summed the absolute values of the low and high uncertainty results when categorizing the magnitude of uncertainty. 
The results of the sensitivity analysis show that more accurate data are urgently needed for commercial/industrial stocks, active power, and usage. Other important factors include the power management enabled rate of displays, desktop computers, terminals, and laser printers, as well as the low power requirements for minicomputers, mainframes, and laser printers

Table A-31. Classification of Commercial/Industrial Input Data According to the Level of Potential Error in Energy Use Calculations Caused by Uncertainty in Input Data

\begin{tabular}{|c|c|}
\hline Total Possible Error in Calculations & Input Data \\
\hline Over 2,000 GWh/year & $\begin{array}{l}\text { - Stock of desktop computers, displays, minicomputers, } \\
\text { mainframes, laser printers, and copiers } \\
\text { - Active power requirements of minicomputers } \\
\text { - Usage of desktop computers, minicomputers, and displays }\end{array}$ \\
\hline From 1,000 to $2,000 \mathrm{GWh} /$ year & $\begin{array}{l}\text { - } \quad \text { Stock of servers and terminals } \\
\text { - } \quad \text { Active power of desktops, mainframes, and displays } \\
\text { - } \quad \text { Low power requirement of minicomputers } \\
\text { - } \quad \text { Usage of minicomputers and terminals } \\
\end{array}$ \\
\hline From 500 to $1,000 \mathrm{GWh} /$ year & $\begin{array}{l}\text { - Stock of inkjet printers and faxes } \\
\text { - } \\
\text { - } \quad \text { Low power power of servers and faxes } \\
\text { - } \quad \text { Ssage of inkjet printent of mainframes and laser printers } \\
\text { - SPM of desktops, terminals and laser printers } \\
\end{array}$ \\
\hline Less than $500 \mathrm{GWh} /$ year & - $\quad$ All the other input data \\
\hline
\end{tabular}

\section{Comparison with Our 1995 Forecast}

Difference between Current Best Estimate and Our 1995 Forecast. We compared our current estimate for commercial office equipment with our 1995 forecast (Koomey et al. 1995) of 1999 electricity consumption by office equipment. Because we did not separate "micro computers"3 into desktop, portable, or server computers in our 1995 forecast, we cannot separately compare our current estimates for those categories with our 1995 forecast. Instead, we combined our current estimate for desktop computers, portable computers, and servers into one category and compared the combined result to the "micro computers" category from the 1995 forecast.

Tables A-32, A-33, and A-34 show our current estimate, our 1995 forecast, and the difference between our current estimate and the 1995 forecast, respectively.

Table A-32. Current Best Estimate of 1999 Energy Use

\begin{tabular}{|l|c|c|c|c|c|c|c|c|c|c|}
\hline Equipment type & $\begin{array}{c}\text { Stock } \\
\text { (thousands) }\end{array}$ & $\begin{array}{c}\text { PA* } \\
\text { (W) }\end{array}$ & $\begin{array}{c}\text { PL* } \\
\text { (W) }\end{array}$ & $\begin{array}{c}\text { PO* } \\
\text { (W) }\end{array}$ & $\begin{array}{c}\text { HA** } \\
\text { (hr/week) }\end{array}$ & $\begin{array}{c}\text { HL** } \\
\text { (hr/week) }\end{array}$ & $\begin{array}{c}\text { HO** } \\
\text { (hr/week) }\end{array}$ & $\begin{array}{c}\text { SPM } \\
(\%)\end{array}$ & $\begin{array}{c}\text { EPC } \\
\text { (kWh/yr) }\end{array}$ & $\begin{array}{c}\text { E } \\
\text { (TWh/yr) }\end{array}$ \\
\hline Micro Computer & 55,970 & 56 & 18 & 1.5 & 24 & 61 & 76 & $32 \%$ & 0 & 11.9 \\
Mini Computer & 1,520 & 1,000 & 500 & 0 & 74 & 76 & 18 & (B) & 0 & 8.9 \\
Mainframe & 96 & 10,000 & 5,000 & 0 & 74 & 76 & 18 & (B) & 0 & 5.6 \\
Display & 47,760 & 85 & 5 & 0.5 & 19 & 61 & 88 & $60 \%$ & 0 & 9.8 \\
Terminal & 10,000 & 75 & 5 & 0.5 & 19 & 61 & 88 & $60 \%$ & 0 & 1.8 \\
Laser Printer & 18,980 & 77 & 25 & 1 & 11 & 118 & 39 & $80 \%$ & 20.0 & 5.4 \\
Inkjet Printer & 20,890 & 17 & (A) & 2 & 71 & (A) & 97 & (A) & 1.1 & 1.6 \\
Copier & 6,530 & 185 & 76 & 8.7 & 28 & 71 & 69 & $68 \%$ & 53.6 & 5.7 \\
Fax & 18,940 & 15 & (A) & 0 & 150 & (A) & 18 & (A) & 1.9 & 2.3 \\
\hline
\end{tabular}

*PA, $\mathrm{PL}, \mathrm{PO}=$ Power requirement in active mode, low-power mode, and off mode, respectively

**HA. HL, $\mathrm{HO}=$ Hours in active mode, low-power mode, and off mode, respectively

\footnotetext{
${ }^{3}$ Micro computers are all computers whose price is less than $\$ 25,000$. Desktop computers, portable computers, and servers are micro computers.
} 
Table A-33. 1995 Forecast for 1999 Energy Use

\begin{tabular}{|l|c|c|c|c|c|c|c|c|c|c|}
\hline Equipment type & $\begin{array}{c}\text { Stock } \\
\text { (thousands) }\end{array}$ & $\begin{array}{c}\text { PA } \\
\text { (W) }\end{array}$ & $\begin{array}{c}\text { PL } \\
\text { (W) }\end{array}$ & $\begin{array}{c}\text { PO } \\
\text { (W) }\end{array}$ & $\begin{array}{c}\text { HA } \\
\text { (hr/week) }\end{array}$ & $\begin{array}{c}\text { HL } \\
\text { (hr/week) }\end{array}$ & $\begin{array}{c}\text { HO } \\
\text { (hr/week) }\end{array}$ & $\begin{array}{c}\text { SPM } \\
(\%)\end{array}$ & $\begin{array}{c}\text { EPC } \\
(\mathbf{k W h} / \mathbf{y r})\end{array}$ & $\begin{array}{c}\mathbf{E} \\
(\mathbf{T W h} / \mathbf{y r})\end{array}$ \\
\hline Micro Computer & 52,790 & 50 & 25 & 0 & 15 & 44 & 109 & $33 \%$ & 0 & 7.5 \\
Mini Computer & 1,514 & 1,250 & 625 & 0 & 74 & 76 & 18 & (B) & 0 & 11.1 \\
Mainframe & 90 & 10,000 & 5,000 & 0 & 74 & 76 & 18 & (B) & 0 & 5.3 \\
Display & 52,790 & 63 & 14.3 & 0 & 30 & 29 & 109 & $47 \%$ & 0 & 8.4 \\
Terminal & 10,000 & 63 & 14.3 & 0 & 30 & 29 & 109 & $47 \%$ & 0 & 1.6 \\
Laser Printer & 27,850 & 80 & 25 & 0 & 8.5 & 50.5 & 109 & $91 \%$ & 14.9 & 3.6 \\
Inkjet Printer & 24,060 & 9 & (A) & 0 & 52 & (A) & 116 & (A) & 1.2 & 0.6 \\
Copier & 7,820 & 190 & 150 & 10 & 30 & 27 & 111 & $38 \%$ & 10.5 & 5.8 \\
Fax & 13,120 & 22.5 & (A) & 0 & 168 & (A) & 0 & (A) & 50.8 & 3.2 \\
\hline
\end{tabular}

Table A-34. Difference between Current Estimate and 1995 Forecast of 1999 Energy Use ( $\Delta$ = Current Estimate -1995 Forecast)

\begin{tabular}{|l|c|c|c|c|c|c|c|c|c|c|}
\hline Equipment type & $\begin{array}{c}\Delta \text { Stock } \\
\text { (thousands) }\end{array}$ & $\begin{array}{c}\Delta \mathbf{P A} \\
(\mathbf{W})\end{array}$ & $\begin{array}{c}\Delta \mathbf{P L} \\
(\mathbf{W})\end{array}$ & $\begin{array}{c}\Delta \mathbf{P O} \\
(\mathbf{W})\end{array}$ & $\begin{array}{c}\Delta \mathbf{H A} \\
(\mathbf{h r} / \text { week) }\end{array}$ & $\begin{array}{c}\Delta \mathbf{H L} \\
(\mathbf{h r} / \text { week) }\end{array}$ & $\begin{array}{c}\Delta \mathbf{H O} \\
(\mathbf{h r} / \text { week })\end{array}$ & $\begin{array}{c}\Delta \mathbf{S P M} \\
(\boldsymbol{\%})\end{array}$ & $\begin{array}{c}\Delta \mathbf{E P C} \\
(\mathbf{k W h} / \mathbf{y r})\end{array}$ & $\begin{array}{c}\Delta \mathbf{E} \\
(\mathbf{T W h} / \mathbf{y r})\end{array}$ \\
\hline Micro Computer & 3,170 & 6 & -7 & 1.5 & 9 & 17 & -33 & $-1 \%$ & 0 & 4.4 \\
Mini Computer & 6 & -250 & -125 & 0 & 0 & 0 & 0 & $(\mathrm{~B})$ & 0 & -2.2 \\
Mainframe & 6 & 0 & 0 & 0 & 0 & 0 & 0 & $(\mathrm{~B})$ & 0 & 0.3 \\
Display & $-5,030$ & 22 & -9.3 & 0.5 & -11 & 32 & -21 & $13 \%$ & 0 & 1.4 \\
Terminal & 0 & 12 & -9.3 & 0.5 & -11 & 32 & -21 & $13 \%$ & 0 & 0.2 \\
Laser Printer & $-8,870$ & -3 & 0 & 1 & 2.5 & 67.5 & -70 & $11 \%$ & 5.1 & 1.8 \\
Inkjet Printer & $-3,170$ & 8 & $(\mathrm{~A})$ & 2 & 19 & $(\mathrm{~A})$ & -19 & $(\mathrm{~A})$ & -0.1 & 1 \\
Copier & $-1,290$ & -5 & -74 & -1.3 & -2 & 44 & -42 & $30 \%$ & 43.1 & -0.1 \\
Fax & 5,820 & -7.5 & (A) & 0 & -34 & (A) & 34 & (A) & -48.9 & -0.9 \\
\hline
\end{tabular}

(A) We did not estimate low-power modes for inkjet printers and faxes.

(B) We did not estimate power management modes for minicomputers and mainframes. Low-power modes of minicomputers and mainframe do not mean power management but rather that peripherals are off while CPUs are on.

Decomposition of Differences. We analyzed the difference between our current estimate and previous forecast to determine the causes of the major differences.

The differences can be decomposed into the following equation by using a Taylor expansion:

$$
\begin{aligned}
& E_{i}^{1999}-E_{i}^{F C}=\left(\frac{\partial E}{\partial S t o c k}\right)_{i}^{F C} \times \Delta \text { Stock }_{i}+\left(\frac{\partial E}{\partial S P M}\right)_{i}^{F C} \times \Delta S P M_{i}+\left(\frac{\partial E}{\partial E P C}\right)_{i}^{F C} \times \Delta E P C_{i} \\
& +\left(\frac{\partial E}{\partial P A}\right)_{i}^{F C} \times \Delta P A_{i}+\left(\frac{\partial E}{\partial P L}\right)_{i}^{F C} \times \Delta P L_{i}+\left(\frac{\partial E}{\partial P O}\right)_{i}^{F C} \times \Delta P O_{i} \\
& +\left(\frac{\partial E}{\partial P A \cdot \partial \text { Stock }_{i}}\right)_{i}^{F C} \times \Delta P A_{i} \times \Delta \text { Stock }_{i}+\left(\frac{\partial E}{\partial P L \cdot \partial \text { Stock }_{i}}\right)_{i}^{F C} \times \Delta P L_{i} \times \Delta \text { Stock }_{i}+\left(\frac{\partial E}{\partial P O \cdot \partial \text { Stock }_{i}}\right)_{i}^{F C} \times \Delta P O_{i} \times \Delta \text { Stock }_{i} \\
& +\left(\frac{\partial E}{\partial P A \cdot \partial S P M}\right)_{i}^{F C} \times \Delta P A_{i} \times \Delta S P M_{i}+\left(\frac{\partial E}{\partial P L \cdot \partial S P M}\right)_{i}^{F C} \times \Delta P L_{i} \times \Delta S P M+\left(\frac{\partial E}{\partial P O \cdot \partial S P M}\right)_{i}^{F C} \times \Delta P O_{i} \times \Delta S P M \\
& +\left(\frac{\partial E}{\partial P A \cdot \partial H A}\right)_{i}^{F C} \times \Delta P A_{i} \times \Delta H A_{i}+\left(\frac{\partial E}{\partial P L \cdot \partial H L}\right)_{i}^{F C} \times \Delta P L_{i} \times \Delta H L_{i}+\left(\frac{\partial E}{\partial P O \cdot \partial H O}\right)_{i}^{F C} \times \Delta P O_{i} \times \Delta H O_{i} \\
& +\left(\frac{\partial E}{\partial \text { Usage }_{i}}\right)_{i}^{F C} \times \Delta \text { Usage }_{i}+\left(\frac{\partial E}{\partial \text { Usage } \cdot \partial \text { Stock }_{i}}\right)_{i}^{F C} \times \Delta \text { Usage }_{i} \times \Delta \text { Stock }_{i}+\left(\frac{\partial E}{\partial \text { Usage } \cdot \partial S P M}\right)_{i}^{F C} \times \Delta \text { Usage }_{i} \times \Delta S P M_{i} \\
& +\left(\frac{\partial E}{\partial \text { Stock } \cdot \partial S P M}\right)_{i}^{F C} \times \Delta \text { Stock }_{i} \times \Delta S P M_{i}+\left(\frac{\partial E}{\partial \text { Stock }^{\prime} \partial E P C}\right)_{i}^{F C} \times \Delta \text { Stock }_{i} \times \Delta E P C_{i} \\
& +\operatorname{Re} \operatorname{sidual}\left(\Delta^{3}\right)
\end{aligned}
$$

where 
E1999 = Current estimate for energy use in 1999

$E F C=$ Forecast in 1995 for energy use in 1999

and

$\left(\frac{\partial E}{\partial U \text { sage }}\right) \times \Delta U$ sage $=\left(\frac{\partial E}{\partial H A}\right) \times \Delta H A+\left(\frac{\partial E}{\partial H L}\right) \times \Delta H L+\left(\frac{\partial E}{\partial H O}\right) \times \Delta H O$

We decomposed the difference between current estimate and forecast of energy use by micro computers, displays, laser printers, inkjet printers, copiers, and faxes in 1999. The results are shown in Table A-35.

Findings. The total difference between the previous forecast and our current estimate is less than $15 \%$. Our current estimate of energy use by microcomputers, displays, laser printers, and inkjet printers is higher than our 1995 forecast. Current estimate of energy use for minicomputers and faxes is lower than our forecast in 1995.

For microcomputers and laser printers, the differences in estimates of usage are the most crucial factor describing the difference in the total results. The difference in usage estimates arose because the rate that equipment is left on during nights and weekends is higher than we expected previously.

For displays, inkjet printers, and minicomputers, the difference in estimates of active-mode power requirements are the most crucial factor describing the difference in the total results. Previously, we predicted that the average power requirement of displays would be $63 \mathrm{~W}$; our current estimate is $85 \mathrm{~W}$. This difference arose mainly because large screen displays (17-inch or larger) have become more popular than previously expected. For inkjet printers, we previously predicted that the average power requirement would be $9 \mathrm{~W}$; our current estimate is $17 \mathrm{~W}$. For minicomputers, we predicted that the average power requirement would be $1,250 \mathrm{~W}$; our current estimate is $1,000 \mathrm{~W}$.

For faxes, differences in stock estimates are the most crucial factor describing the difference in the total results. 
Table A-35. Decomposition of Differences between Current Estimate and 1995 Forecast of 1999 Energy Use (GWh/year)

\begin{tabular}{|c|c|c|c|c|c|c|}
\hline Decomposition Term & $\begin{array}{c}\text { Micro } \\
\text { Computer } \\
\end{array}$ & Display & $\begin{array}{c}\text { Laser } \\
\text { Printer }\end{array}$ & $\begin{array}{c}\text { Inkjet } \\
\text { Printer }\end{array}$ & Copier & Fax \\
\hline$\left(\frac{\partial E}{\partial \text { Stock }}\right)^{F C} \times \Delta$ Stock & 452 & -804 & $-1,142$ & -80 & -957 & 1,439 \\
\hline$\left(\frac{\partial E}{\partial S P M}\right)^{F C} \times \Delta S P M$ & 35 & -489 & 443 & 0 & -612 & 0 \\
\hline$\left(\frac{\partial E}{\partial E P C}\right)^{F C} \times \Delta E P C$ & 0 & 0 & 142 & -2 & 337 & -642 \\
\hline$\left(\frac{\partial E}{\partial P A}\right)^{F C} \times \Delta P A$ & 341 & 2,762 & -54 & 533 & -171 & -850 \\
\hline$\left(\frac{\partial E}{\partial P L}\right)^{F C} \times \Delta P L$ & -259 & -338 & -23 & 0 & -310 & 0 \\
\hline$\left(\frac{\partial E}{\partial P O}\right)^{F C} \times \Delta P O$ & 451 & 150 & 159 & 291 & -59 & 0 \\
\hline$\left(\frac{\partial E}{\partial U \text { sage }}\right)^{F C} \times \Delta U$ sage & 3,253 & 1,658 & 3,248 & 215 & 3,663 & -276 \\
\hline$\left(\frac{\partial E}{\partial P A \cdot \partial \text { Stock }}\right)^{F C} \times \Delta P A \times \Delta$ Stock & 21 & -263 & 17 & -70 & 28 & -378 \\
\hline$\left(\frac{\partial E}{\partial P L \cdot \partial \text { Stock }}\right)^{F C} \times \Delta P L \times \Delta$ Stock & -16 & 32 & 7 & 0 & 51 & 0 \\
\hline$\left(\frac{\partial E}{\partial P O \cdot \partial \text { Stock }}\right)^{F C} \times \Delta P O \times \Delta$ Stock & 27 & -14 & -51 & -38 & 10 & 0 \\
\hline$\left(\frac{\partial E}{\partial P A \cdot \partial S P M}\right)^{F C} \times \Delta P A \times \Delta S P M$ & -4 & -221 & -23 & 0 & 41 & 0 \\
\hline$\left(\frac{\partial E}{\partial P L \cdot \partial S P M}\right)^{F C} \times \Delta P L \times \Delta S P M$ & 7 & -93 & 3 & 0 & -245 & 0 \\
\hline$\left(\frac{\partial E}{\partial P O \cdot \partial S P M}\right)^{F C} \times \Delta P O \times \Delta S P M$ & 0 & 0 & 0 & 0 & -4 & 0 \\
\hline$\left(\frac{\partial E}{\partial \text { Usage } \cdot \partial \text { Stock }}\right)^{F C} \times \Delta$ Usage $\times \Delta$ Stock & 196 & -158 & $-1,035$ & -28 & -606 & -123 \\
\hline$\left(\frac{\partial E}{\partial \text { Usage } \cdot \partial S P M}\right)^{F C} \times \Delta$ Usage $\times \Delta S P M$ & 15 & -578 & 590 & 0 & -674 & 0 \\
\hline$\left(\frac{\partial E}{\partial P A \cdot \partial H A}\right)^{F C} \times \Delta P A \times \Delta H A$ & 174 & 365 & -37 & 198 & -105 & 91 \\
\hline$\left(\frac{\partial E}{\partial P L \cdot \partial H L}\right)^{F C} \times \Delta P L \times \Delta H L$ & -101 & -399 & -30 & 0 & -500 & 0 \\
\hline$\left(\frac{\partial E}{\partial P O \cdot \partial H O}\right)^{F C} \times \Delta P O \times \Delta H O$ & -139 & -30 & -102 & -48 & 32 & 0 \\
\hline$\left(\frac{\partial E}{\partial \text { Stock } \cdot \partial S P M}\right)^{F C} \times \Delta$ Stock $\times \Delta S P M$ & 2 & 47 & -141 & 0 & 101 & 0 \\
\hline$\left(\frac{\partial E}{\partial \text { Stock } \cdot \partial E P C}\right)^{F C} \times \Delta$ Stock $\times \Delta E P C$ & 0 & 0 & -45 & 0 & -56 & -285 \\
\hline Residual $\left(\Delta^{3}\right)$ & -3 & -244 & -146 & -20 & -47 & 40 \\
\hline$\Delta E$ & 4,451 & 1,383 & 1,780 & 949 & -81 & -983 \\
\hline
\end{tabular}




\section{Network Equipment}

\section{Lifetimes of Network Equipment}

Network equipment is very new, and equipment lifetimes are unknown, although they are expected to be short since network equipment evolving rapidly. We assumed that the lifetime for all types of network equipment is four years.

\section{Domestic Sales Revenue from Network Equipment}

First, we estimated worldwide sales revenue from network equipment during the past four years for each type based on the Dell'Oro Group's quarterly press releases (Dell'Oro Group 19961999). Second, we allocated worldwide sales revenue to the U.S. and other countries based on the ratio of the number of host names in the U.S. to those in other countries. Table A-36 shows the domestic sales revenue for network equipment from 1996 to 1999.

Table A-36. Domestic Sales Revenue from Network Equipment, 1996-1999 (million US\$)

\begin{tabular}{|ll|c|}
\hline Equipment Type & Domestic Sales Revenue (million US\$) \\
\hline WAN & Router & 1,130 \\
& Switch & 5,458 \\
\hline \multirow{2}{*}{ LAN } & Router & 13,210 \\
& Switch & 19,932 \\
& Access Device & 6,662 \\
& Hub & 4,228 \\
\hline
\end{tabular}

\section{Ratio of Power Requirement to Price for Network Equipment}

We first chose a representative model for each type of network equipment. We selected CISCO products as the representative model of all types of network equipment except hubs because the prices and power requirements of CISCO products are readily available. We selected a $3 \mathrm{COM}$ product as the representative model for hubs because of its popularity. Next, we estimated the power requirement for each representative model by assuming that the real power requirement is half of the rated power requirement. Then, we estimated the price for each representative model based on prices quoted from several online shopping sites. Finally, we calculated the ratio of power requirement to price.

Table A-37 shows the representative model and its ratio of power requirement to price for each type of network equipment.

Table A-37. Ratio of Power Requirement to Price for Selected Network Equipment

\begin{tabular}{|ll|l|c|}
\hline Equipment Type & Representative Model & $\begin{array}{c}\text { Ratio of Power Requirement } \\
\text { to Price (W/\$1000) }\end{array}$ \\
\hline WAN & Router & CISCO 7500 & 5.0 \\
& Switch & CISCO BPX 8620 & 5.0 \\
\hline LAN & Router & CISCO 2500 & 6.0 \\
& Switch & CISCO 2900 & 7.5 \\
& Access Device & CISCO AS5300 & 5.0 \\
& Hub & 3COM SuperStack 2 & 17.5 \\
\hline
\end{tabular}




\section{Reasonableness of Estimates of Energy Use by LAN Routers and Switches}

Network equipment is dedicated to computers on the network, so there must be a correlation between the total power requirement of network equipment and the number of computers on the network. We surveyed LBNL's network and estimated what portion of the power requirement of LAN routers and switches is dedicated to each computer at LBNL by dividing the total power requirement of all LAN routers and switches by the total number of computers (including desktop, portable, and server computers). Similarly, we estimated what portion of the power requirement of LAN routers and switches is dedicated to each computer in the U.S. by dividing the total power requirement of all LAN routers and switches by the total number of commercial and industrial computers in the U.S. (including desktop, portable, and server computers). Finally, we compared these two values and evaluated the reasonableness of our estimate. Table A-38 shows the results of this comparison.

Table A-38. Comparison of the Power Requirement of LAN Routers and Switches Per Computer in the U.S. and LBNL

\begin{tabular}{|l|c|c|}
\hline Estimate & U.S. & LBNL \\
\hline Total Power Requirement of LAN Routers and Switches & $228.7 \mathrm{MW}$ & $16,360 \mathrm{~W}$ \\
Number of Computers & $60.7 \mathrm{million}$ & 5,000 \\
Power Requirement of LAN Routers and Switches per Computer & $3.77 \mathrm{~W} / \mathrm{unit}$ & $3.27 \mathrm{~W} / \mathrm{unit}$ \\
\hline
\end{tabular}




\section{Additional References for the Appendix}

Business Technology Association, 2000. "Forecast of Installed base of servers, by Dedicated Use, Application or File." Available online at: $<\underline{\text { http://www.bta.org/main/newsinfo/cmptrind/lansrvrs.shtml }>\text {. }}$

Dell'Oro Group, 1996-1999. "Press Releases." Available online at: $<$ http://www.delloro.com/PRESS/press_releases.shtml $>$.

Graff, R. and B. Fishbein. 1991. "Reducing Office Paper Waste". INFORM. New York.

Morrisette, S. 1999. "The Digital Decade." Forrester Research. Published online at http://www.forester.com/ER/Press/Talking.

Newsham, G.R., and D.K. Tiller. 1994. "The Energy Consumption of Desktop Computers: Measurement and Saving Potential.” IEEE Transactions on Industry Applications. July.

Nordman, B., M.A. Piette, K. Kinney, and C. Webber. 1997. "User Guide to Power Management in PCs and Monitors.” LBNL-39466. January.

Szydlowski, R.F. and W.D. Chvala. 1994. "Energy Consumption of Personal Computer Workstations.” PNL Report-9061. Feburary.

U.S. Census Bureau. 1999. "Estimates of Housing Units, Households, Households by Age of Householder, and Persons per Household." Available at

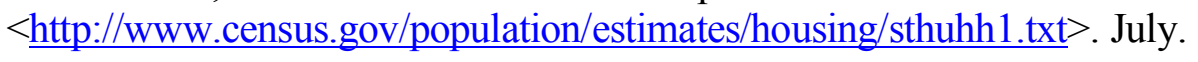

Pulp \& Paper. 1995. Pulp \& Paper 1995 North American Factbook. Miller-Freeman. San Francisco, CA.

Webber, C.A., R.E. Brown, and J.G. Koomey. 2000. "Saving s Estimates for the ENERGy STAR® Voluntary Labeling Program." Energy Policy 28 (2000), 1137-1149. Also see

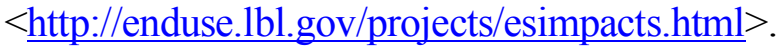

